\title{
On the Arrangement of the Vascular Strands in the 'Seedlings' of Certain Leptosporangiate Ferns'.
}

\author{
BY
}

\author{
S. E. CHANDLER, D.Sc., A.R.C.S., F.L.S. \\ Assistant in the Colonial Collections at the Imperial Institute.
}

With Plates XVIII, XIX, and XX.

BEFORE the publication of Jeffrey's ${ }^{2}$ account of the development of $B$ the vascular system of Pteris aquilina, very little attention had been paid to the ontogeny of the 'polystelic' type of vascular anatomy. Gerard $^{3}$, Van Tieghem ${ }^{4}$, and Leclerc du Sablon ${ }^{5}$ had described the very earliest transitional stages of several ferns, but in the majority of cases the descriptions were of the shortest character, and merely concerned with the anatomical changes involved in the transition of the diarch rootstructure to the solid protostele occurring at the base of the young stem. These researches, although in themselves of considerable interest, threw very little light upon the processes involved in the vascular elaboration, and it was not until Jeffrey published his account of Pteris that definite and accurate information upon this important point was available.

Since the appearance of Jeffrey's paper, much work has been done along exactly similar lines for other ferns, both by that author himself, and also by Boodle, Gwynne-Vaughan, Farmer and Hill, and others. As a result, botanists at the present time have a good general idea of the development of a typical dictyostelic vascular organization, though the interpretation of the facts observed varies to no small degree.

In spite, however, of the considerable amount of work which has been done in this direction, definite information with regard to particular species

1 Accepted by the Senate of the University of London as a Thesis for the Degree of Doctor of Science.

2 Morphology of the Central Cylinder of Angiosperms. Trans. Canad. Inst., 6. x 900.

3 Recherches sur le passage de la racine à la tige. Ann. Sc. Nat., $\sigma^{e}$ sér., t. xi.

${ }^{4}$ Sur la Polystélie. Ann. Sc. Nat., $7^{e}$ sér., t. iii.

${ }^{5}$ Recherches sur la formation de la tige des Fougères. Ann. Sc. Nat., $7^{\ominus}$ sér., $t$. xi.

[Annals of Botany, Vo1. XIX. No. LXXV. July, 1905.] 
is surprisingly scanty, and there can be no doubt that it is just such knowledge which is required at the present time, if the different views which still exist upon the 'stelar' question are to be successfully harmonized.

It was in the hope of making a contribution-necessarily a small oneto such a knowledge that the present work was undertaken. Nearly twenty ferns have been examined, mostly belonging to Polypodiaceae, a family which will doubtless prove of considerable interest in connexion with vascular questions, not only on account of its numerical richness in species, but also on account of the great variety of forms occurring within its boundaries.

The majority of the plants examined were obtained, through the kindness of Prof. Farmer, from Messrs. James Hill and Son, of Edmonton, who afforded the writer every facility for gathering plants of the different ages required.

The methods employed in the investigation were generally of a very simple character. Whenever possible, the plants were embedded in paraffin and serial sections obtained in the usual way. In some cases, however, owing to the presence of sclerenchyma, the celloidin method was resorted to, and occasionally, when even this was impossible, the ferns were cut by hand.

The sections were always double-stained with saffranin and haematoxylene. The well-known method of lightly staining with haematoxylene, and subsequently 'blueing' with ammonia, proved of great value for the differentiation of sieve-tubes, especially in very young plants.

\section{DOODIA ASPERA, R. $\mathrm{Br}^{1}$.}

The primary root of this plant is of the diarch type so general among the ferns. In the transitional region the xylem plate, by the development of tracheides upon its sides, becomes oval and finally more or less circular in section, and, at the same time, the phloem is gradually differentiated as a continuous sheath surrounding the solid xylem rod (Fig. 197). At a slightly higher level, two or three parenchyma cells appear in the centre of the xylem (Fig. I98), quickly followed by one or two well-marked sievetubes (Fig. I99). The early appearance of internal sieve-tubes is a point of some interest, since it indicates that almost from its very commencement the primary pith is, in reality, phloem; in other words, it is vascular, as opposed to non-vascular tissue. This point, however, will be referred to later.

Just before the first leaf-trace is given off, the sieve-tubes increase to about four or five in number, taking up a central position in the internal

1 The nomenclature adopted throughout is that of Hooker's 'Synopsis Filicum,' except when otherwise stated. 
phloem, so that at this level we have a relatively broad band of xylem surrounded externally by phloem, and containing at its centre a core of phloem in which the sieve-tubes appear as a central strand surrounded by two or three layers of phloem parenchyma. The pericycle consists of a single layer of cells whose radial walls are not in regular seriation with those of the somewhat poorly differentiated endodermis. The fundamental tissue is composed of parenchyma containing a considerable amount of starch, and, in young plants at any rate, is characterized by a complete absence of the sclerenchyma which is so striking a feature in the seedlings of some other ferns.

The first leaf-gap is formed in a very simple manner, a sector of the vascular strand becoming detached and passing outwards as the leaf-trace. On the completion of the trace, the external and internal phloem become continuous round the horns of the xylem arc, by the differentiation of sieve-tubes at these regions. The endodermis merely bridges the leaf-gap, there being no indication of any 'dipping in' of this layer (Fig. 200). It is somewhat difficult to decide whether the internal phloem 'takes any part in ' the formation of the leaf-trace, but the evidence points to such being the case; expressed more correctly, the leaf-strand is concentric even at its junction with the cauline system, the adaxial moiety of its phloem being continuous with the internal phloem strand, and the abaxial portion with the external phloem sheath of the vascular arc. During the separation of the leaf-trace, a root-strand joins the cauline system at a point almost exactly opposite the leaf, its junction taking place in a perfectly simple way. Very soon after the completion of the leaf-trace, the gap is closed in the well-known manner by the gradual extension of the horns of the gap towards one another, the result being the appearance of a ring of xylem surrounded by phloem, and enclosing a central strand of sieve-tubes and parenchyma (Fig. 20I). It should be noticed that there is no internal endodermis or phloeoterma. The sieve-tubes still form a solid core in the internal phloem, but this condition of things is not long maintained, for very soon preparations are made for the exit of the second leaf-trace, and at this point a few parenchyma cells appear in the core of sieve-tubes. It is still noticeable, however, that the latter are by far the most numerous and conspicuous elements of the intraxylary tissue.

In the majority of cases, the second leaf-trace is formed in exactly the same way as the first, although individual variations are frequent. The corresponding root-strand then joins the vascular system. The third and fourth leaf- and root-traces are formed in a perfectly normal manner, but in connexion with the fourth leaf-gap we have, for the first time, a differentiation of a blunt projection of ground-tissue between the edges of the gap, the ground-parenchyma being separated from the vascular tissue by a continuation of the normal endodermis. In other words, the endodermis 
'dips into' the leaf-gap. As we pass upwards, the ground-parenchyma encroaches more and more upon the vascular tissue, so that the internal phloem loses its strand-like character, and appears as a layer of sieve-tubes and parenchyma lining the internal concavity of the xylem, the horns of which gradually approach one another as the gap is closed (Figs. I-3). While these changes are taking place, and before the closing of the gap, the xylem, at a point almost exactly opposite the latter, breaks into two, sieve-tubes and parenchyma appearing between the two portions; the continuity of the endodermis is not affected. As in many similar cases, to be described below (an especially good example occurring in Lomaria gibba), this new break in the xylem is in reality the first preparation for the exit of the next leaf-trace, for very soon after its appearance a concentric strand of vascular tissue is nipped off from each of the cauline arcs, the changes involved in the process being indicated in Figs. 3-5. The two concentric strands, each of which is surrounded by its own endodermis, pass outwards as the leaf-trace, which is thus double at its junction with the cauline system. Long before the strands enter the petiole, however, union has taken place, so that the leaf-stalk itself possesses a single concentric vascular strand.

In most other cases of ferns possessing multiple leaf-traces it has been found that the latter do not appear suddenly, as in the case just described, but only after the few preceding leaf-traces have shown a very complete series of transitions between the primary single leaf-trace and the more complex system supplying the later leaves. The only hint at such a transitional series occurring in Doodia aspera was the occasional slightly bilobed character of the xylem of the previous leaf-strand.

As soon as the exit of the double leaf-trace is complete, the former gap closes and a root enters. As will be seen from Figs. 6 and 7, the cauline system at this region of the stem consists of but a single curved strand. A consideration, however, of the vascular system as a whole up to this level will establish its essentially tubular (siphonostelic) character. This is rendered more obvious by subsequent changes, for very quickly the single strand divides into two parts, one much larger than the other (Figs. 8 and 9). From each a small concentric strand is nipped off, the two forming the next double leaf-trace, which, as before, is single before it reaches the petiole, though in this case the two xylem patches are separated by phloem for a short distance at the base of the leaf-stalk. The larger of the two cauline strands then divides into two (as in Fig. I2), and the next leaf-trace is formed in exactly the same way as its predecessors.

It is unnecessary to follow the further development of the vascular system; its final siphonostelic condition has been reached, and subsequent changes are merely an elaboration of the stage just described. 


\section{NePHRODIUM SPINULOSUM v. Dilatatum, Hk ${ }^{1}$.}

The series of changes occurring in the transitional region of this plant resemble those of Doodia aspera, and need be described in no great detail.

The primary root is diarch, and somewhat quickly passes into the protostelic condition. A few parenchyma cells, followed later by one or two well-marked sieve-tubes, appear at the centre of the xylem strand, their appearance being succeeded by the differentiation of the first leaftrace, which takes place in the simple manner described above for the previous fern. The gap remains open through a considerable distance, and only closes just before the exit of the second leaf-trace. The phloem is continuous round the edges of the gap, and, on the closing of the latter, the cauline system consists of an amphiphloic vascular rod. The pericycle consists of relatively large squarish cells; it is somewhat variable in thickness, not only at any one particular level, but also at different parts of the plant, a double layer of cells often persisting through several consecutive sections. The endodermis is narrow, but very conspicuous.

The first three or four leaf-traces are differentiated in the same simple manner, and involve the formation of no real leaf-gap, the break in the vascular system being merely bridged by the endodermis. After the exit of about the fourth leaf-trace, however, the gaps become more pronounced, and at the level of the sixth leaf the xylem has assumed the shape of a curved band, into the bay of which the endodermis 'dips' sharply. The phloem, especially that portion of it lining the concavity of the xylem, is particularly well differentiated.

At a slightly higher level, the seventh leaf-trace leaves the cauline system as the central portion of the curved vascular band, with the result that, after the exit of the trace, the stem is supplied with two concentric vascular strands, each surrounded by a separate endodermis.

The xylem of the last-mentioned leaf-trace has a distinctly bilobed character-an indication of the double or multiple nature of the laterformed traces.

After the closing of the seventh leaf-gap, the vascular arc again breaks into two portions, and the next leaf-strand is double at its origin, though single before it enters the leaf-stalk. By the splitting of one of the vascular strands before the previous gap has been repaired, we have the appearance of three concentric strands in the cauline system at this particular level, and later elaborations of an exactly similar type quickly result in the adult dictyostelic structure being reached. 


\section{LOMARIA GIBBA, Labill.}

The diarch xylem plate of the primary root very quickly becomes oval and finally circular in section, sheathed externally by a complete layer of phloem derived from the tangential extension of the two original phloem strands. A characteristic feature of the xylem is the presence of a considerable amount of parenchyma among the tracheides, and even in the earliest stages small parenchyma cells (persisting, however, through only two or three sections) appear scattered in various parts of the small xylem strand. The pericycle consists of a single layer of small cells crowded with contents, and is succeeded by a very definite endodermis. As is so often the case, the stem bends somewhat sharply at the transitional region, and the changes occurring at this level are frequently difficult to follow. Oblique sections, however, clearly show that a few parenchyma cells with densely staining contents are differentiated at the centre of the xylem, the parenchymatous core often being temporarily connected with the external phloem by irregular radial extensions.

On the stem resuming the vertical position, two or three well-marked sieve-tubes appear in the central parenchyma, and immediately the first leaf-trace passes out, its structure and mode of exit being essentially similar to that described for Doodia aspera. The resulting gap, however, was generally found to differ from the corresponding gap of nearly all other ferns examined, in being of relatively large size and remaining open through some considerable distance. The usual state of affairs is the formation of a small, quickly closed gap.

The gap is repaired in the usual way, viz., by the gradual extension of the vascular tissue tangentially, and we have a ring of xylem surrounded by phloem and containing a strand of the same tissue, the two phloems having been in continuity through the leaf-gap (Figs. I3, I4).

The second leaf-trace is formed exactly opposite the first and in a perfectly similar manner (Fig. I5). Like its predecessor, the trace is a very simple concentric strand, consisting of a few tracheides surrounded by phloem. The third leaf-trace, however, has a distinctly bilobed strand of xylem, a fact hinting at the occurrence of double leaf-traces to supply the later leaves. The preparations for the third leaf-trace are also of some interest. The xylem of the vascular ring breaks temporarily just before its exit, the break being effected by an 'encroachment' of the internal phloem; the actual gap, however, is occupied merely by parenchyma. As will be seen below, this breaking of the xylem foreshadows the preliminary division of the cauline strands which plays so important a part in connexion with the formation of the later leaf-traces.

At a slightly higher level, and before the repair of the last leaf-gap, the xylem breaks immediately opposite the latter by an encroachment 
of the internal phloem exactly as before. In this case, however, the break is larger, and occupied not merely by parenchyma, but by sieve-tubes as well. The external and internal phloem thus become continuous through the break, which is, of course, a preparation for the exit of the next leaf-strand.

The gap in the xylem gradually increases in size, and a root-trace joins one of the xylem arcs in the usual way; its entrance is followed at an immediately higher level by the closing of the third leaf-gap (Fig. 18). In some cases the break in the xylem was temporarily bridged over by a single row of two or three tracheides, but the latter persisted through only a few sections. Very soon preparations are made for the actual exit of the leaf-trace. A strand of tracheides is nipped off from each of the xylem horns, and the two strands, separated by a narrow band of sievetubes and surrounded by common phloem and endodermal sheaths, pass out as the leaf-trace (Figs. 19-21). The single nature of the leaf-traces is therefore still maintained.

In a small proportion of the plants examined, a shallow and indefinite 'ground-tissue pocket' was associated with the exit of the leaf-trace just described, an irregular patch of endodermal cells appearing between the cauline strand and the outgoing petiolar bundle, just before the latter was quite free. The pocket was of so simple a character, compared with similar structures fully described elsewhere for other ferns, that no further description is necessary. Its occurrence, however, is of interest, since it emphasizes the essential uniformity between apparently somewhat different types of transitional changes.

The fourth and following leaves occur in more rapid succession than their predecessors, and, during the exit of the fourth leaf-trace, the xylem at a point exactly opposite the latter is encroached upon by the central phloem and broken into two portions, the break, as before, being occupied by phloem (Figs. 20-22). The fourth leaf-gap then closes, and the fifth trace is given off, as its predecessor, from the two horns of the broken xylem ring; it is still of the simple type, though the two xylem patches are separated by a comparatively wide band of phloem and parenchyma. Immediately opposite the leaf-gap, a root-strand joins the cauline system.

The break formed in the initial stages of the exit of the sixth leaftrace is much wider than in previous cases, though the endodermis merely bridges the gap, as shown in Fig. 24. Higher up, however, the xylem strands become further separated, and the sieve-tubes of the internal phloem, which up to the present have occupied a more or less central position in the 'pith,' are now arranged lining the internal surface of the xylem. At the same time the phloem-parenchyma cells become larger and hence more conspicuous.

As the two portions of the xylem become more separated, ground- 
parenchyma is differentiated between them, the endodermis being pushed, as it were, before the advancing ground-tissue (Fig. 25). The two vascular strands (the previous leaf-gap has not yet been closed) do not at this level become completely separated by the ground-tissue, so that we have, in transverse section, two patches of xylem each surrounded by phloem, the whole being ensheathed in a common pericycle and endodermis (Fig. 25).

At the moment when the complete separation of the two vascular strands by the ground-tissue seems almost effected, a concentric strand is gradually nipped off from each of the horns bounding the enlarged sixth break in the vascular tissue ; sometimes the strands were found to be nipped off simultaneously, but in other plants they became free from the cauline system at different levels, a state of affairs found to be very common in connexion with such multiple leaf-traces.

The two strands, each of which is surrounded by its own endodermis, never fuse together, as in previous cases, but remain quite separate and pass out to form the first double leaf-trace. During the complete separation of this trace, the larger of the two cauline strands begins to divide into two (Fig. 28), one portion fusing with the remaining main strand and thus closing, at last, the fifth leaf-gap. Fig. 29 shows that at this level the cauline system consists of two concentric vascular strands each surrounded by a separate endodermis. Subsequently a double leaf-trace is formed in the manner indicated in Figs. 29-3I, and we have the final appearance of three cauline strands by the division of one of the original two, the actual changes being represented in Figs. 33-35.

Subsequent developments consist of a gradual elaboration of the vascular system, but the processes involved in the actual formation of the leaf-traces are essentially the same as those described above; that is to say, we have a splitting of the vascular tissue followed by the separation of the two petiolar strands from the adjacent horns, and the subsequent closing of the previous leaf-gap. The siphonostelic character of the vascular system of this plant is therefore quite evident.

A very considerable amount of variation was met with in the earliest transitional stages, necessitating the examination of a comparatively large number of specimens before the varying appearances presented could be reduced to some common plan. As mentioned above, the xylem of Lomaria gibba possesses a considerable amount of parenchyma among the tracheides, and it seems almost certain that the variations met with can be attributed to this fact, for the parenchyma cells appear in the xylem of the very youngest plants. The following exceptional case is interesting. A single parenchyma cell, quickly followed by three or four others, appeared in the normal diarch plate of the root. At a higher level the ordinary protostelic structure occurred, but the parenchyma cells now appeared as a band stretching across the xylem, and continuous at either end with 
the external phloem. The xylem was thus divided into two portions, and the appearance of another parenchymatous band, almost at right angles to the first, divided the xylem into three portions, the whole strand for several successive sections almost exactly simulating the appearance of a triarch root. At a slightly higher level the two bands had taken up a more or less central position in the xylem as two parenchymatous islands, one gradually dying out, the other maintaining its size, and, after one or two transitory connexions with the external phloem, appearing with a central strand of a few sieve-tubes. This occurred just before the first leaf-trace, which was separated from the cauline strand as a sector of vascular tissue by the development of parenchyma cells between the external and internal phloem.

In other plants similar variations occurred, all obviously connected with the parenchymatous nature of the xylem. A description of these variations, though interesting in itself, is unnecessary.

\section{Lomaria Spicant, Desv.}

The writer is indebted to Mr. T. G. Hill for an abundant supply of material of this plant. The transition from root to stem is somewhat rapid, but takes place in the usual manner. The root is diarch, and the protostele of the stem soon possesses a few parenchymatous cells at its centre. Just before the exit of the first leaf-trace one or two sieve-tubes appear in the parenchyma, so that at this stage we have, as before, a central strand of phloem surrounded by xylem, which, in its turn, is ensheathed in a cylinder of phloem. The most striking feature of the anatomy of the younger plants is the thick-walled character of the cells of the fundamentaltissue. The pitted walls are deep brown in colour, and the cell contents consist largely of densely staining tannin. The fundamental and vascular tissues are thus sharply contrasted.

The first two or three leaf-traces leave the amphiphloic protostele in a perfectly normal way, the external and internal phloem becoming continuous at the gap, which is merely bridged by the somewhat smallcelled endodermis.

At the level when the endodermis bridges the third or fourth leaf-gap, and while the latter is still unclosed, one or two cells appear in the central phloem in the neighbourhood of the gap. The cells have thickened, yellowish, glistening walls and are thus readily distinguishable from the phloem. These cells, as we pass upwards, are immediately succeeded by a few others which have all the characters of the fundamental-tissue, viz., hard, thick, pitted walls, and tannin-impregnated contents. The most interesting fact, however, is that this group of fundamental-tissue cells is surrounded by an endodermis exactly resembling the outer endodermis in its small narrow cells, and which would readily escape anything but careful 
observation (Fig. $5 \mathrm{I}$ ). At this stage preparations are made for the exit of the next leaf-trace, which is formed opposite the previous one and exactly above the preceding root. The strand of fundamental-tissue gradually assumes a more central position in the phloem, and a few sections higher up has increased in size and taken up a position near the outgoing leaftrace. The previous leaf-gap is not yet closed. As will be seen from Figs. 54-57, the leaf-trace when complete is a simple concentric strand surrounded by an endodermis, the inner half of which is derived from the outer part of the endodermis surrounding the central strand of fundamental-tissue, and not from the external endodermis by a process of ' nipping in,' as is so generally the case.

As soon as the leaf-trace is completed, we have the inner half of the inner endodermis continuous with the outer endodermis round the horns of the xylem arc, the internal strand of fundamental tissue thus effecting a junction with the main mass of ground-parenchyma (Figs. 55-57).

The previous leaf-gap then gradually closes, and finally we have an arc of xylem including a patch of phloem, which is encroached upon at the leaf-gap by the ground-tissue. The latter is limited at this region by an endodermis having quite a different origin from a mere 'invagination.' As we pass upwards, the encroachment of the ground-tissue upon the central phloem becomes less and less, and finally the endodermis merely bridges the gap.

The sixth leaf-trace is formed in exactly the same way as the previous one, with the exception that the internal strand of fundamental-tissue is, from the first, in close proximity to the leaf-trace with which it is to be finally associated. After the trace is completed, however, the 'invagination' of the ground-tissue is not diminished as before, but increased, the more so as the preparations for the next leaf-trace advance (Figs. 61, 62). This leaftrace differs from the preceding in being double and not single, and consequently different processes are involved in its exit.

In Fig. 60 we see the xylem arc broken at $x$ in preparation for the trace, the two portions being separated by a band of phloem. This break is in reality the unclosed fifth leaf-gap, which is never fully repaired. In Figs. 61 and 62 the fundamental-tissue has advanced upon the medullary or internal phloem, which finally becomes relegated to a position merely lining the internal surface of the tracheary strand. This advance of the ground-parenchyma is complete, as it were, in Fig. 63 , and we have two strands of vascular tissue separated from one another by the conspicuous fundamental-tissue, and each surrounded by phloem, pericycle, and endodermis. At a stage shown in Fig. 64, the two strands which will form the future trace are beginning to be nipped off, and it will be observed that the two horns of the xylem arc have approached one another, and that there is but a single fused endodermal layer between them. As the leaf- 
trace becomes more advanced this endodermal layer disappears, and the mature leaf-trace at this stage consists of two vascular strands surrounded by a common endodermis. The further processes involved in the exit of this first double leaf-trace are illustrated in Figs. 65-67.

In older plants the double character of the leaf-trace is maintained, but each strand is surrounded by its own endodermis. This modification entails no additional complications at the actual exit of the trace, as will be seen below. As soon as the first double leaf-trace is completed the previous leaf-gap is repaired, and indications of the next appear in a breaking of the xylem arc into two portions, one considerably larger than the other. From each of these two vascular strands a portion is nipped off, each surrounded by its own endodermis, the structure of the older leaf-traces mentioned above being thus attained. The accompanying changes are indicated in Figs. 68-71. In Figs. 72 and 73 the two portions of the xylem are again joining, the junction being followed by a new split, to the horns of which the new leaf-trace is attached. Subsequent changes are merely a repetition and elaboration of the same process.

The occurrence, in connexion with the third or fourth leaf-trace, of a strand of fundamental-tissue surrounded by an endodermis is of considerable interest. A single transverse section at this particular level exhibits a structure closely approximating to that of a typical 'gamostele' as illustrated by the rhizome of Marsilia. Again, support is apparently afforded to Jeffrey's hypothesis of the primitive amphiphloic stele with an internal endodermis. A mental picture of the whole region of the leafgap will, however, at once show these ideas to be erroneous. What we really have is the formation of a fundamental-tissue pocket which is ensheathed on all sides by an endodermal layer, and hence closely resembling the 'endodermal pockets' occurring in Schizaea dichotoma', S. malaccana ${ }^{2}$, and Lindsaya ${ }^{3}$. There can be no doubt that the first two or three small cells with yellowish glistening walls which appear in connexion with the third or fourth leaf-trace are really the endodermal cells sheathing the apex of the cone or elongated dome of ground-tissue laid down from the growing point in the medullary phloem ${ }^{4}$.

In the above account, the roots have been practically omitted for the sake of brevity and clearness. It will be sufficient to say that the roots are perfectly normal, and that the leaf-traces are always formed, in young plants at any rate, directly over the position of the last root, and very soon after the latter has joined the stelar system.

1 Boodle, Comparative anatomy of the Hymenophyllaceae, Schizaeaceae and Gleicheniaceae, iv. Further observations on Schizaea. Annals of Botany, xvii.

${ }^{2}$ Tansley and Chick, On the anatomy of Schizaea malaccana. Annals of Botany, xvii.

3 Tansley and Lulham, On a new type of Fern-stele, \&c. Annals of Botany, xvi.

- The term 'fundamental-tissue pocket' or 'ground-tissue pocket' has been employed since the writer believes that such a term more correctly indicates the essential nature of the phenomenon. 


\section{BLeChNum BRASILIENSE, Desv.}

The ontogeny of the vascular system of this plant so closely resembles that of Lomaria Spicant that further description is unnecessary.

The radiciferous strands described by Trécul ${ }^{1}$ and Lachmann ${ }^{2}$ as occurring in this plant were not noticed, probably owing to the examples examined being comparatively young.

\section{Asplenium bulbiferum, Forst.}

In investigating this plant it was intended to compare the transitional changes in the seedling with those in the adventitious buds which are so common on the mature fronds. Unfortunately, the seedlings could not be obtained, and hence the following account is concerned with the adventitious buds alone. It is hoped the seedlings may soon be available and the necessary comparison made.

The buds arise as outgrowths of the leaf-tissue in the immediate neighbourhood of the swollen end of a vein supplying the large sorus. The suitability of such a point of origin is obvious. The young bud possesses a simple concentric vascular strand, connected with the vein of the leaf and surrounded by a well-marked endodermis. The strand is oval in section, and the xylem, consisting of tracheides and parenchyma in about equal proportions, shows no distinct protoxylem elements. The phloem completely ensheathes the xylem, and the sieve-tubes are well marked. The pericycle and endodermis have their cells in seriation, as is the case in so many ferns. The endodermis itself is often two or three cells deep locally, and has conspicuous brown cell-walls.

The ground-parenchyma is quite normal in structure but the more external cells are frequently meristematic, their division resulting in the formation of radial rows of cells, which, however, soon lose their radial arrangement.

In older stages, the parenchyma of the xylem has taken up a central position, and sieve-tubes very quickly appear, frequently as a strand at the centre. We thus have the usual amphiphloic structure so general in the other cases examined, but in the absence of a primary root, the preceding protostelic condition naturally does not occur.

The first leaf-trace is quite simple, a sector of the vascular ring affording the necessary strand. The gap is immediately closed. It is interesting to note, in connexion with the later traces, that the xylem of the trace as it leaves the cauline strand is somewhat bilobed.

${ }^{1}$ Remarques sur la position des trachées dans les Fougères. Ann. Sc. Nat., $5^{e}$ sér., xii,

2 Contributions, etc., Thésis présentée à la Faculté des sciences de Paris, sér. A, no. I16, I889. 
A root-trace then joins the cauline system approximately opposite the previous leaf, but hardly is its connexion complete when the vascular ring opens, and from each of the two horns thus formed a strand is constricted off to form a double leaf-trace, a condition hinted at in the bilobed appearance of the xylem of the first leaf-trace. The two leaf-bundles pursue a curved course through the cortex, leaving the cauline system almost horizontally. During their exit, a group of endodermal cells appears in the internal phloem between the xylem arc and the outgoing trace, and at a slightly higher level an endodermal ring surrounds a group of large parenchyma cells closely resembling the fundamental-tissue. At the leaf-gap, this inner endodermis joins up with the external sheath, which, owing to the horizontal and band-like leaf bundles, presents at this level the somewhat peculiar appearance represented in Figs. I 52-I 54 . We thus have in this plant, as in Lomaria Spicant, a pocket of fundamental-tissue laid down in the region of the leaf-gap, and shut off from the vascular system by an endodermis.

After the completion of the trace, the two strands of which quickly unite to form a single petiolar bundle, the cauline strand has the form of a curved band, which receives a root-trace opposite the last leaf. The xylem then immediately breaks into two strands, the previous leaf-gap remaining open. The whole cauline strand, however, is still surrounded by a common endodermis (Figs. I 56, I 57).

The next leaf-trace is double, and formed from the horns guarding the new break in the xylem by a process of simple constriction. There is no pocket of fundamental-tissue formed in connexion with this leaf-trace, whose extreme simplicity of origin is somewhat masked by the difference in levels at which the two components leave the cauline system, and by their horizontal course through the cortex. As before, the final trace is single, but its double origin is obvious (Figs. 1 58, I 59).

After the exit of the trace, the ground-tissue gradually separates the two vascular arcs, each of which finally possesses its own endodermal sheath, as in Figs. I59 and I60. One of the vascular arcs receives a root-trace, and, before its junction with the latter is really complete, divides into two parts; a fusion of one part with the remaining original cauline vascular strand occurs, and a leaf-trace is formed by the nipping off of two strands exactly as before (Figs. I62-I64). The whole process is then repeated again and again, the double leaf-strands remaining separate for increasingly longer periods, fusion finally occurring in the base of the petiole.

In connexion with the later-formed leaf-traces, it was found that the division of the cauline strand commences just before the entry of the corresponding root-trace, and consequently the latter has a double insertion upon the cauline system. The later roots, too, have a somewhat 
unusual path in the cortex, an upward curved course being that most commonly adopted.

It is unnecessary to describe in any detail the later processes in the elaboration of the vascular system. The cauline strands increase in number by repeated fraction, and the mature dictyostelic condition is very quickly attained.

In one or two plants examined it was noticed that small strands which ended blindly in the ground-tissue at a higher level were occasionally given off from the cauline system. Similar strands were also found to occur in Polypodium aureum.

\section{Aspidium Tsus-Simense, Hk.}

The transitional processes of this fern are of a very simple character and will be described merely in outline. Passing upwards in the young plant, we find the root-strand changing into the protostelic condition in the normal way, though the completion of the change is much longer deferred than is generally the case. Internal phloem is differentiated just before the exit of the first leaf-trace, which is formed in the usual simple manner. Fig. I65 represents the cauline system after the completion of the first trace. It will be seen that although the gap is not yet repaired, a pocket of fundamental-tissue has been differentiated in the phloem at the centre of the amphiphloic strand. The vascular tissue later bulges outwards at a point opposite the gap, the protruding portion, in which the xylem is seen to be arranged in two distinct tracts, soon passing outwards as the second leaf-trace. The inner and outer parts of the ground-tissue become continuous after the exit of the leaf-trace. The curved vascular band subsequently becomes more strongly convex, and, as before, the 'back' of the arc separates from the lateral portions as we pass upwards, to supply the third leaf with a single petiolar bundle. The later formation of the first double leaf-trace is illustrated in Figs. I 70, I 7 I.

The mature vascular organization is the result of the elaboration, along ordinary lines, of the simple dictyostelic structure obtaining at this level, and need be described at no further length.

\section{Poly podium AUReum, L.}

The dorsiventral rhizome of this fern creeps along the surface of the ground, bearing upon its upper surface two rows of leaves which are more or less arranged in pairs. The internodes between consecutive pairs are of considerable length. The change from the radial to the dorsiventral habit is well shown in a fairly young rhizome, in which the conical base is seen to bend sharply at right angles as it rapidly increases in diameter. The adult horizontal position of the rhizome is soon reached. 
The rhizome is creamy-white in colour and thickly clothed with long narrow brown ramenta, which at the growing point are greenish and so densely packed together that they may be removed $e n$ bloc as a firm conical cap, the protective value of which is obvious. After the removal of the ramenta, the surface of the rhizome is seen to be minutely pitted, each pit indicating the place of insertion of a ramentum. The ramenta are narrowly triangular in outline and consist of a single layer of cells with yellowishbrown walls. Each is inserted upon the rhizome at the base of the shallow pit by means of a short multicellular stalk, beyond which the base of the ramentum is produced backwards as two auricle-like lobes with densely papillose margins, sharply contrasting with the irregularly toothed margin of the body of the ramentum. The contour of the cell-walls differs in different parts of the scale; in the lamina the cells are irregularly rectangular in outline, contrasting with the cells in the region of the stalk, which are much smaller and hexagonal, with walls of a deep-brown colour. The cells of the auricular regions have sinuous contours.

The primary root of Polypodium aureum is, as usual, diarch. The vascular strand is extremely simple, consisting of but a few elements, which are, however, very definite. In the transitional region a striking difference from the usual course of events is exhibited. Instead of the diarch plate gradually becoming rod-like to form the solid protostele of the young stem, the xylem extends laterally and becomes strongly curved. The phloem extends round the horns of the xylem, but the sieve-tubes are often absent from the extremities for a few sections. One or two root-traces join the cauline strand at or near the middle of its convex surface, and then the first leaf-trace is formed in a very simple and quite exceptional manner, by the nipping off of a small part of one of the vascular horns. The first trace is concentric, and in several plants was approximately equal to the remaining cauline strand. Thus, in striking contrast to other ferns examined, there is no central phloem differentiated at the centre of the solid protostele, and the first leaf-trace leaves no corresponding gap. The absence of early leaf-gaps is, of course, by no means exceptional outside the Polypodiaceae, familiar examples being afforded by the Schizaeaceae, Gleicheniaceae (Boodle), Osmundaceae (Osmunda, Faull, Todea, Seward and Ford), and Marattiaceae (Angiopteris, \&c., Farmer and Hill).

Polypodium aureum has already received the attention of Leclerc du Sablon ${ }^{1}$ and Jeffrey ${ }^{2}$. The former investigator has correctly described the very earliest stages in the transition, but announces and figures the later appearance of a strand of parenchyma at the centre of the xylem rod. This however has been denied by Jeffrey, who was unable to find any such

1 Loc. cit.

${ }^{2}$ Structure and development of the stem in the Pteridophyta and Gymnosperms. Phil. Trans., ser. B, vol. $\operatorname{cxcv}(1902)$. 
parenchyma. It will be seen that the writer's investigations confirm the results arrived at by the latter author.

The cauline strand increases somewhat in size, but is still in the form of a curved band, and the second leaf-trace is formed in a manner precisely similar to the first, but from the other extremity of the vascular tissue (Figs. 9I-95). Soon after the completion of the leaf-trace, a root-strand joins the vascular band, which quickly divides into two parts, each being in section an arc of xylem and phloem surrounded by a pericycle and endodermis. One of these secondary strands is considerably larger than the other, and from it the third leaf-trace is nipped off just as in previous cases. The two strands then approach one another and fuse, the junction being maintained for a short distance; they soon separate again, however, and from one of them the next leaf-trace is formed as before, but more or less opposite the previous trace (Figs. 96-IO2). This radial arrangement of the leaf-traces in the young plant is of considerable interest, since the most striking feature of mature specimens is the dorsiventrality of the rhizome, the leaves being arranged in two rows on the upper surface and the roots confined to the lower and lateral surfaces. A root-trace soon joins one of the cauline strands after the exit of the leaf-trace, and then the augmented strand divides into two portions, one of which unites temporarily with the remaining original cauline bundle (Figs. 103-109); as before, the separation is connected with the formation of the next leaf-trace.

The unusual length of the internodes makes it a matter of some little difficulty to clearly realize what is actually taking place in connexion with the formation of the leaf-traces. In spite of the fact that the protostelic and the subsequent amphiphloic conditions of the transitional region do not obtain in this fern, the somewhat simple siphonostelic (phyllosiphonic) nature of its vascular system is quite obvious as soon as two or three leaf-traces are formed, although, as stated above, the length of the internodes, together with the small size of the cauline strands, makes this fact somewhat difficult of realization. Instead of the leaf-trace being formed in the normal way, we have a splitting of the vascular strand followed by the constricting off of a portion to form the leaf-trace. The subsequent fusion (really the closing of the elongated gap), followed by a new splitting, demonstrates the essentially siphonostelic nature of the vascular system of this plant. It is interesting to note that a somewhat similar series of changes occurs, as an exceptional circumstance, in connexion with some of the early leaf-traces of Aspidium falcatum (q.v.), although in this case the transitional region presents the normal protostelic and amphiphloic conditions. To return. The fifth leaf-trace is the first to hint at the double traces which are so characteristic of the mature plant. It is derived from the two portions of the divided cauline strand by the nipping off of a small concentric bundle from each; one half of the leaf-trace is formed at 
a considerably lower level than the other, as is so often the case (Figs. I09, IIO). The two leaf-strands pass gradually outwards through the cortex, and, in doing so, approach one another and finally fuse, leaving the stem as a single bundle. The fifth leaf, therefore, is supplied with a single trace which has an obviously double origin. The sixth leaf-trace is also double in origin, and formed exactly as before, being preceded by the usual closing of the elongated gap and subsequent splitting. Although the mature trace is single, its double origin is hinted at in the bilobed character of its xylem.

After the gap is closed, the subdivision of the vascular strands proceeds apace. Instead of a single strand dividing into two, the strands divide, one into two, the other into three parts, each being surrounded by its own endodermis. The division of the actual strand is nearly always preceded by the constriction of the xylem into the required number of parts, the portions of the xylem being separated by phloem parenchyma and occasionally sieve-tubes. Fig. I 8 represents the appearance of the stem in transverse section after the sixth trace has passed out. The next two or three leaf-traces are formed in exactly the same way as before, but retain their double character for successively longer periods. Soon, however, the leaf-traces have an apparently simple origin. At about the eighth or ninth leaf, the stem in transverse section presents six or seven strands embedded in the ground-tissue. The leaf-trace is formed by the nipping off of a vascular strand from each of two neighbouring cauline strands, one being separated from the cauline bundle at a considerably lower level than the other. Both soon leave the stem to enter the petiole, but the exit is gradually delayed in succeeding leaf-traces. It is this fact which explains the apparent anomaly in the formation of the leaf-strands in older plants.

In a moderately sized rhizome there are from twelve to fifteen vascular strands, and at the node two of these are seen to pass out bodily into the petiole. This apparently is quite different from the process obtaining in young plants, but a complete series of sections through two of the long internodes shows that the leaf-trace formations are essentially the same in both cases. In the later internodes, the vascular strands divide and fuse several times, but strands from which the last leaf-trace was derived remain separate for some considerable distance. Finally, however, they subdivide, and the lesser strands fuse among themselves, so that the leaf-gap is closed. The true siphonostelic character of the vascular system is therefore maintained. Two neighbouring strands then divide into two, one much in advance of the other, and the two daughter strands run through the remainder of the internode and apparently belong to the cauline system. At the next node, however, they pass outwards to the petiole and form the leaf-trace as described above. It will thus be evident that the later 
traces are formed in essentially the same way as those of the young plants, their true origin being rendered somewhat difficult of realization by the greatly elongated internodes. The series of changes is represented in Figs. I23-I28. The petioles of the later leaves are generally supplied with two main bundles and one or two smaller ones, which, however, fuse into two strands soon after their entrance into the petiole. As regards the leaf-trace itself, then, we find that the earliest leaves are provided with a single strand; later, the trace has a double origin, but a single bundle enters the leaf-stalk; and, finally, the leaf-strands remain separate for successively longer periods until the mature condition is reached, in which two chief strands enter the petiole, fusing a short distance higher up.

Several variations of the normal early transitional changes described above were noted. In two or three plants the xylem of the diarch plate broke into three parts, which were surrounded by a common phloem sheath. One of the xylem strands, surrounded by phloem and endodermis, passed out as the first leaf-trace, while the two remaining strands quickly fused, or separated from one another as concentric strands which reunited to form a single concentric rod at a slightly higher level.

In plants of all ages it occasionally happened that small concentric strands left the cauline system, and, bending sharply outwards, ended blindly in the ground-tissue, generally just beneath the epidermis. A similar state of affairs was noted for Asplenium bulbiferum.

\section{Petiole.}

The petiole of a moderately sized leaf is almost circular in section, and possesses that peculiar wiriness so characteristic of many fern leaf-stalks. There is a single vascular strand embedded in a ground-tissue limited externally by an epidermis. The latter consists of a layer of cells square in section, and with extremely thick lignified walls almost completely obliterating the cell cavity.

The ground-tissue is composed of hexagonal parenchyma, but the cells of the outer layers are elongated and strongly sclerosed, affording to the leaf-stalk the stiffness mentioned above. The walls of these mechanical cells are bright red in colour and minutely pitted; the stratification is particularly well marked. The cells remain living for some considerable time, protoplasm and large nuclei being constantly found to be present. The somewhat small intercellular spaces were carefully examined for any indications of the cellulose pegs or outgrowths described by Boodle and others as occurring in similar positions in certain ferns, but such structures seemed to be quite absent.

The petiolar bundle is small and surrounded by an extremely wellmarked endodermis, the outer tangential walls of which are strongly sclerosed and of great thickness. The inner tangential and radial walls 
are quite normal. The position of the latter, exactly opposite the radial walls of the pericycle cells, demonstrates the origin of the two layers from common mother-cells. The pericycle is two cell-rows deep, except at the protoxylem groups, where it is only one layer thick. Its cells have crowded contents and large nuclei.

In the lower portion of the petiole there are two (or more, v.s.) vascular strands, each possessing a curved xylem plate with generally a single protoxylem group. The large scalariform tracheides are surrounded by a layer of parenchyma cells with deeply-staining contents. The parenchyma is succeeded by the phloem, which is arranged in two chief masses, one on either side of the xylem plate; the sieve-tubes are of the normal type and very prominent, staining intensely with haematoxylene, especially if subsequently treated with ammonia. Round the ends of the xylem plate, the phloem is reduced to a single row of sieve-tubes intermixed with a few parenchyma cells (Fig. 204). The two bundles gradually approach one another, the first stage of the final fusion being the inclusion of the two strands within a common endodermis. The curved xylem bands are situated back to back, separated by phloem, and with the protoxylems widely diverging. A junction is gradually effected, resulting in a $\mathbf{Y}$-shaped strand of xylem with a phloem patch in each of the three bays; the protoxylems occupy the apices of the arms of the $\boldsymbol{Y}$ (Figs. 205-207). The actual junction of the bundles takes place at successively higher levels in the later leaves, and in large petioles there are from three to six bundles which are separate throughout. After the junction of the bundles in the earlier leaves, the endodermis cells become even more conspicuous than before, owing to the further thickening of their outer tangential walls. The thickening and lignification frequently extends also along the radial walls of the next outer layer of cells.

\section{Periderm.}

In one or two of the plants examined, frequent patches of periderm were noticed. As the cells outside the periderm were broken and disorganised, there seems to be little doubt that the rhizome had been accidentally injured at these places, and that the injury had been followed by the formation of wound-periderm. As noted by De Bary ${ }^{1}$, periderm is of extremely rare occurrence in ferns, and, when present, generally seems to be connected with the presence of wounds. Periderm has been described by Holle ${ }^{2}$ as occurring in the root and rhizome of Botrychium, and more recently, Brebner ${ }^{3}$ finds wound-periderm of somewhat frequent occurrence in Marattiaceae.

${ }_{1}$ Comparative Anatomy, p. 108.

${ }^{2}$ Ueber Bau und Entwicklung der Vegetationsorgane der Ophioglosseen. Bot. Zeit., 1875.

${ }^{3}$ On the anatomy of Danaea and other Marattiaceae. Annals of Botany, xvi. 
The periderm presented the appearance of a large patch of thinwalled cells in radial rows, the origin of which could be traced to a very narrow phellogen just beneath the crushed cells of the wounded area (Fig. 208). Very little external tissue seems to have been formed by this phellogen, and it was quite evident that the cells of the ground-tissue beneath the phellogen also divided directly. This is exactly the state of affairs found by Holle to exist in Botrychium.

The changes undergone by the vascular system in the transitional region, as described above, present some striking points of difference from the usual course of events. Instead of the transformation of the diarch xylem plate of the root into a solid strand, a later appearance of a central patch of phloem, and finally the formation of a leaf-gap, we have what is practically the root-strand nipping off a simple concentric leaf-trace directly, without any preliminary appearance of a central pith of phloem, and without the formation of a leaf-gap.

The absence of gaps in connexion with the formation of early leaftraces is, as pointed out above, a phenomenon for which it is easy to find a parallel, but the division of the cauline strand itself, after the exit of the first few traces, is so strikingly different from the normal course of events as to warrant, at first sight, the assumption that in Polypodium aureum a type of transition obtains which is fundamentally distinct from that occurring in the majority of Polypodiaceae. It has been shown above, however, that in the later-formed regions of the rhizome, an essentially siphonostelic vascular system is present, and in the light of this evidence it is highly probable that the apparent anomaly existing in the young plant can be explained. The earliest transitional changes present no real difficulty; the leaf-traces which do not involve the formation of leaf-gaps are given off directly from a cauline strand, in which, for some reason, the xylem has maintained the plate-like character it possessed in the root. This was found to be by no means without a somewhat similar parallel, even among the relatively small number of ferns examined by the writer. For instance, in some of the seedlings of Pteris Winsetti and Doodia aspera, the xylem at the level of the first trace had a distinctly oval outline in transverse section, and this occurred occasionally also in other plants. The splitting of the cauline strand is perhaps a point more difficult of explanation. The writer, however, regards the splitting merely as an anticipation of the characteristic double nature of the later leaf-traces. Such a splitting, previous to the actual nipping off of the petiolar bundles, seems to be of very general occurrence in connexion with such double traces (cf. Doodia aspera, \&c.), and is indeed the most obvious preparation for their formation. If this view of the transitional changes be the correct one, the essentially siphonostelic character of the young vascular system is 
established, and Polypodium aureum is brought into line with the normal type.

The early stages of Polypodium aureum find an almost exact parallel in the young seedlings of Ceratopteris thalictroides. Miss Ford ${ }^{1}$ has given an account of the transitional changes occurring in this interesting fern, and describes the gradual change of the root-strand into a normal protostele, and the subsequent exit of a few simple leaf-traces. Soon, however, the cauline strand apparently breaks into two, just as in the case described above. Unfortunately, Miss Ford was unable to follow out the later changes, and infers that in Ceratopteris we have evidence of a kind which lends support to the essential idea of Van Tieghem's theory, viz., the branching of the original single cauline strand, the protostele. With this inference the present writer is inclined to disagree. It is probable that if older stages had been examined, the breaking of the stem strand would have been found to have been in intimate association with the formation of a leaf-gap, a view supported by the evidence of Polypodium aureum, and by the text figure of Miss Ford's paper (p. I06), which clearly shows the bundle system of Ceratopteris to be a vascular tube interrupted by elongated and exaggerated leaf-gaps.

The occurrence of similar early transitional changes in the two plants is of some interest, since it supports the conclusion arrived at by Miss Ford with regard to the systematic position of Ceratopteris, viz., that the plant finds its nearest relations among Polypodiaceae.

Since the publication of a preliminary note ${ }^{2}$ on the present work, the writer has received a communication from Miss Ford confirming the account given above of the early transitional stages of Polypodium aureum. Miss Ford further observed a few variations from the normal type, most of which were also noted by the writer.

\section{Nothochlaena sinuata, Kaulf.}

The transitional changes occurring in this plant proved to be of a most interesting type. The primary root is diarch, but the vascular elements are somewhat irregularly arranged and by no means well differentiated, the latter being especially the case with the sieve-tubes. Considerable variation occurs in the earliest transitional changes, but generally the xylem plate becomes more or less circular in transverse section, and, as usual, a small strand of parenchyma is differentiated at its centre. It is extremely difficult to say whether sieve-tubes occur among the parenchyma cells; some of the latter are smaller than their neighbours, and

1 The anatomy of Ceratopteris thalictroides, L. Annals of Botany, xvi.

${ }^{2}$ New Phytologist, May 1904. 
might possibly be interpreted as sieve-tubes, but, on the whole, it is probable that sieve-tubes are not differentiated in the central 'pith' until after the first leaf-trace. The latter is quite simple, but of relatively large size, leaving a gap which remains open through a considerable distance, a character which is maintained throughout the plant. The corresponding root is quite normal, and, just before the second leaf-trace, definite sievetubes appear scattered in the enlarged pith. After the closing of the second gap, the stem presents a characteristic appearance in transverse section. The xylem ring is very narrow (consisting of only two or three rows of tracheides), and encloses a relatively large pith of phloem in which the sieve-tubes are very conspicuous. In these early stages it frequently happens that isolated tracheides, sometimes in small groups, are differentiated in the central phloem, a point of some interest which will be referred to in connexion with Nephrodium setigerum. Immediately outside the xylem is a very regular row of parenchyma cells, followed by an almost continuous single layer of sieve-tubes. The most striking feature, however, is the pericycle, which is composed of two or three layers of large squarish cells with conspicuous nuclei and readily-staining contents. The endodermis is well marked, but its cells are not always in exact seriation with those of the pericycle, as so commonly occurs. The parenchyma of the ground-tissue is thin-walled except at the periphery, where the walls are sclerosed and deep red in colour.

The first four root- and leaf-strands are formed in a perfectly normal manner, the xylem gradually dilating and enclosing the enlarged central strand of phloem. In connexion with the exit of the fifth or sixth leaftrace we have the formation of a typical ground-tissue pocket as described for other forms. The vascular ring becomes strongly oval in outline, and towards one end of the central phloem a group of two or three endodermal cells appears. At a slightly higher level the endodermal cells surround a strand of thick-walled parenchyma very similar in appearance to the sclerotic elements of the ground-tissue (Fig. I74). As in similar cases, the inner and outer endodermis become continuous at the exit of the trace, and the ground-tissue is differentiated to a considerable depth in the central phloem (Figs. I74, I75). The apparent encroachment of the groundparenchyma upon the vascular tissue increases until the phloem and pericycle merely line the concavity of the xylem, as indicated in Fig. 176. At a slightly higher level the leaf-gap is closed, and we have the very interesting appearance represented in Fig. I77. The resemblance of this isolated section to a similar section of Gwynne-Vaughan's true solenostelic ferns is very striking.

During these changes the xylem ring has become thicker, and exactly opposite the previous leaf-gap begins to bulge outwards in preparation for the next trace. The formation of the latter is indicated in Figs. I77 
and 178 , in which it is seen that the bulged portion of the vascular tissue goes out as the leaf-strand, resulting in the union of the inner and outer endodermis. The gap remains open for some considerable distance, the vascular ring increasing in diameter, and, before the gap is closed, the next leaf-trace is given off from the back of the xylem arc in the manner indicated in Fig. I79, with the result that the cauline system now consists of two strands. The xylem of the leaf-trace is at first in two distinct strands, a fact hinting at the double origin of the later traces. Soon after the exit of the petiolar bundle, the previous leaf-gap closes as far as the vascular tissue as a whole is concerned, the horns of the xylem, however, not fusing, but remaining separated by two or three parenchyma cells (Fig. I80). This is no doubt to be regarded as a preparation for the next leaf-trace, which is definitely double, as shown in Fig. I8I. The closing of the previous gap is immediately followed by the breaking of the cauline vascular strand into two (Figs. 182, 183). The following leaf-trace is double, the two strands being nipped off from the vascular horns resulting from the fractionation of the cauline system (Fig. 184). Two or three rootlets join the stem at this level, and one of the vascular strands then breaks into two portions, a division which is rapidly followed by a fusion of one portion with the undivided strand, and the subsequent formation of another leaftrace as shown in Figs. $185^{-1} 87$.

The two cauline strands then effect a junction, but quickly separate again. As will be seen from Fig. 187 , the diameter of the vascular tube is only slightly less than that of the stem as a whole, the ground-tissue being reduced to a mere band, the outer layers of which are very strongly sclerosed. The xylem has increased in width, but is still comparatively narrow ; the phloem is normal, and the pericycle maintains its multiseriate character. The endodermis is extremely well marked, especially that portion of it lining the concavity of the vascular arc, a condition of things no doubt to be correlated with the fact that large numbers of intercellular spaces occur in the loosely arranged central ground-parenchyma. Before the last leaf-gap is closed, the vascular arc again breaks into two, and a new double leaf-trace is formed in the manner already described. The two bundles, which are separated by a strand of sclerenchyma, leave the cauline system very gradually, and their separation from it is not complete until the previous leaf-gap has been repaired. At a level immediately above, the vascular band again breaks, first into two and subsequently into three parts (Fig. I 89), and during its division several roots join the vascular system. After the entry of the roots, the two largest of the vascular strands again unite (Fig. 190), and, while the exit of another leaf-trace is being effected, the remaining cauline strand also effects a junction with the curved band thus formed.

Subsequent changes are of a very interesting character, and result from 
the branching of the stem at this level. The branching takes place into two such equal parts that one is inclined to infer that true dichotomy must obtain, though this point has not been settled. Fig. 192 represents the stage at which the three cauline strands have completely united; the separation of the leaf-trace is also seen to be taking place. Before the latter is effected, however, the cauline system appears, as we pass upwards, to be 'pinched in' at its centre (Fig. 193). The constriction is completed immediately after the leaf-trace leaves the vascular system, with the result that we have the appearance of two nearly independent solenostelic structures (Fig. I94). In one plant examined, the two rings were completely separate before the stem actually bifurcated (Fig. 196), though the usual state of affairs is for the stem to branch immediately the separation of the vascular rings seems about to occur.

Each of the two branches will therefore be seen to possess at its base a vascular structure, which, in transverse section, presents a typical solenostelic appearance, such as occasionally occurs in the stem before bifurcation takes place. As in the latter case, however, the condition is a very transitory one, the complete rings soon breaking at corresponding points (Fig. 195) in preparation for the insertion of a pair of leaf-strands. From this point onwards, the vascular organization resembles, in main outline, that of the stem before the region of branching, and will be described at no further length.

The method of branching in Nothochlaena simuata closely resembles that occurring in Schizaea dichotoma and Pteris incisa, as described by Boodle $^{1}$, and Tansley and Lulham ${ }^{2}$ respectively. In Pteris the processes involved in the branching are considerably more complex than those obtaining in Schizaea or Nothochlaena, but in all three cases we have the occurrence of dichotomy accompanied by the formation of a median leaf-trace.

As shown in Figs. 187, 192, 194, the ground-tissue in all but the youngest plants consists of two sharply contrasting portions. A narrow band immediately outside the outer endodermis is composed of soft-walled cells, as is the whole of the portion surrounded by the almost complete vascular ring. The peripheral part, however, is composed of small cells, the thick walls of which are coloured a deep reddish-brown, contrasting in a striking manner with the colourless thin-walled parenchyma and with the vascular tissue.

1 Comparative anatomy of the Hymenophyllaceae, Schizaeaceae, and Gleicheniaceae. IV. Further observations on Schizaea. Annals of Botany, xvii.

${ }^{2}$ The vascular system of the rhizome and leaf-trace of Pteris aquilina, L., \&c. New Phytologist, iii, 1904. 
NePhrolepis CORdifolia, Baker (N. TUberosa, Hk.).

The upright, sometimes horizontal, rhizome of this fern gives rise to numerous thin runners or stolons, which bear at intervals scaly tuberous bodies, and many branching adventitious roots. The stolons themselves, especially when young, are often more or less tuberous, and vary in thickness in different parts of their length.

The root exhibits the usual diarch structure, possessing a well-marked endodermis, and a pericycle of varying width. The cells of the cortex are not sclerosed to any remarkable extent. The early transition to a solid protostele takes place in the usual way, the stem bending somewhat sharply at this region; this is by no means an uncommon occurrence, as pointed out elsewhere. A few parenchyma cells are differentiated in the centre of the protostele, and the first leaf-trace is then given off. The trace consists of but a few elements, being practically a continuation of one of the protoxylem groups of the cauline strand together with a little phloem. The leaf-gap is very small, and, in one or two plants examined, no gap at all was left by the first leaf-trace. The external phloem at this stage is poorly differentiated, the identification of the sieve-tubes being a matter of considerable difficulty. This fact probably explains the apparent absence of sieve-tubes in the central pith until after the third leaftrace, a state of affairs somewhat at variance with that found in the majority of other ferns examined. It frequently happens, however, that the pith is continuous with the external phloem by means of parenchymatous strands extending through the xylem, and in all probability the pith is really to be regarded as phloem in which the sieve-tubes are by no means well differentiated.

The first three leaf-traces are formed in the simple manner indicated above, and the accompanying root-traces join the cauline strand in the usual way. Soon, however, the latter begins to increase in size, though it is still quite small and presents two protoxylem groups which are in much the same position as the protoxylem groups of the root. The pericycle now becomes more definite, and is usually two rows deep, its outer cells fitting exactly upon those of the endodermis. At this level, the vascular tissue supplying the first stolon is differentiated, and joins the cauline system in a way very similar to that of a root; in fact, in a cursory examination, it is merely its size which distinguishes the stolon-strand from a root-trace. Its structure, however, is very similar to that of the stem at this level, except that a definite central pith is not present, parenchyma cells occurring scattered throughout the xylem. The stolon itself may be regarded as the result of an abrupt branching of the stem.

After the junction of the stolon with the stem, the cells of the pith (which up to this level have frequently had a somewhat scattered arrange- 
ment in the central part of xylem) become definitely arranged in a small excentric group, and well-marked sieve-tubes, two or three in number, appear among them. The fourth leaf-trace, quite simple and leaving but a small gap, is then given off exactly opposite the stolon. The gap is merely bridged by the endodermis. Just before the trace is differentiated, an isolated section presents an appearance very similar to that described by Tansley and Miss Lulham for Lindsaya ${ }^{\mathbf{1}}$, the excentric position of the internal phloem being very striking. The explanation of this appearance is, of course, very simple, since the vascular tissue of the stolon, although in perfect union with that of the stem, lies alongside the latter for some distance as a kind of keel (Figs. I33, I34). Gradually, however, the union of the two strands becomes more perfect, and the cauline strand once more assumes its cylindrical condition. The leaf-gap is very quickly closed, and a root, with densely sclerosed cortical tissue, then joins the stem at a point opposite the leaf.

As soon as the stem-strand has regained its normal cylindrical condition, sieve-tubes can no longer be distinguished in the pith, the cells of which resume their scattered arrangement among the central tracheides of the xylem. The somewhat indefinite external sieve-tubes show a tendency to arrange themselves in groups, a feature which is more or less constant in older plants. The next change is the somewhat sudden re-grouping of the parenchyma cells to form a central patch in the xylem, followed by the appearance of a few sieve-tubes. At the same time the pericycle increases in width, the cells of its inner layers not being in radial rows with the cells of the outer layer, which, as before noted, are in seriation with the endodermal cells.

The vascular strand has meanwhile increased considerably in size, and the next leaf-trace, though still small, is much larger than its predecessors. It consists of an arc of xylem surrounded by phloem, and leaves a gap which is very quickly closed. The second stolon then joins the stem, its vascular tissue appearing as an immense root-trace. As before, its junction occurs exactly opposite a new leaf-strand, whose exit leaves a gap into which the ground-tissue is differentiated to a slight depth. A transverse section of the stem at this level shows a rounded mass of tracheides and xylem parenchyma with a shallow gap on one side containing sievetubes and parenchyma, which also form a continuous sheath round the xylem as a whole. The ground-tissue, dipping slightly into the gap, is very striking, since its strongly sclerosed polygonal cells contrast sharply with the very definite small-celled endodermis. The phloem in the leafgap occupies an approximately central position in the xylem below the level of the stolon, its excentricity, as before, being solely due to the augmentation of the cauline vascular tissue by the stolon bundle (Fig. I 35). 
In connexion with the fifth or sixth leaf-trace there is a formation of a regular ground-tissue pocket very similar to that already described for other ferns. A group of endodermal cells appears between the outgoing leaf-trace and the main strand, and at a slightly higher level we have a patch of strongly sclerosed cells surrounded by an endodermal sheath. At the exit of the leaf-trace the inner endodermis becomes continuous with the outer, just as in previous cases. The leaf-gap does not close, but, if anything, becomes wider as the next stolon joins the stem; a root-trace enters immediately opposite the gap. After the junction of the stolon and root-strands with the cauline system, the latter in transverse section appears as an arc of xylem (largely parenchymatous), with a broad and shallow gap into which the conspicuous fundamental-tissue dips sharply, but to no great depth (Fig. I 36 ). At a higher level the ground-tissue is differentiated further into the gap and the vascular tissue appears as a reniform strand. The middle portion of the xylem then becomes much attenuated, consisting of only one or two rows of tracheides, and, with its accompanying phloem, bulges out in the manner indicated in the diagrams 137,138 . The fundamental-tissue still further encroaches upon the vascular tissue, but gradually loses its highly sclerotic character, except that portion actually between the horns of the vascular arc, the cells of which are extremely thick-walled. Figs. 140-142 represent the subsequent changes. The attenuated portion of the vascular tissue becomes separated from one of the two main masses, and finally the whole strand divides into three, the arc-like narrow portion passing out as a leaf-trace. The remaining strands then gradually approach and finally fuse, though the vascular portions, surrounded by a common endodermis, remain separated by pericyclic parenchyma for some little distance.

Just before the union of the two cauline strands, one of the latter, viz., that from which the leaf-trace first separated, gives off a portion of its vascular tissue which, as a small strand, joins the leaf-trace at a slightly higher level. This is the first indication of the multiple leaf-traces occurring in mature plants, all previous leaf-strands having been simple. As soon as the union of the cauline strands is complete, another stolon is formed in the usual way, its formation being followed by a redivision of the vascular tissue into two portions. Each of the latter then separates off a small strand, one at a much lower level than the other; a third strand is then nipped off, so that the leaf-trace has three bundles instead of two as before. The three bundles ultimately fuse into a horseshoe-shaped strand.

Subsequent changes consist of a further fractionation of the vascular system, and the gradual elaboration of the leaf-traces. 


\section{Structure of the Young Stolons.}

The structure of the young stolon is essentially the same as that of the stem at the level at which its junction with the latter is effected. The xylem contains a large amount of parenchyma, and possesses three or four peripheral protoxylem groups. A short distance behind the apex the latter are well marked, the large thin-walled tracheae of the metaxylem occupying the central portion of the strand. The phloem, with fairly conspicuous sieve-tubes, which show a tendency to arrange themselves in groups as in the stem, forms a complete sheath round the xylem. An older stolon shows a more or less sclerotic fundamental-tissue contrasting sharply with the small-celled epidermis. The well-marked endodermis, the cells of which are in seriation with those of the pericycle, is surrounded by two or three layers of extremely thick-walled ground-tissue cells. The xylem is still largely parenchymatous, but the tracheae are in three main groups, each with peripheral protoxylem elements. The phloem and pericycle call for no special description, except that the latter does not vary in thickness to any great extent as in the stem.

\section{NePHROdiUm SETIGERUM, Baker.}

The earlier transitional changes of Nephrodium have been described by Leclerc du Sablon ${ }^{1}$ in $N$. molle. Only very young plants were examined, however, and the writer has been able to make a more complete study of $N$. setigerum. The root is diarch, and its transition to the solid protostele of the young stem is, on the whole, normal. The phloem, however, takes a considerably longer time than usual to completely surround the xylem rod, and generally the phloem sheath is not complete until one or two parenchyma cells have appeared in the centre of the xylem. Sievetubes are very quickly differentiated in the pith, taking up a central position, so that we have internal phloem present before the exit of the first leaf-trace. It is a point of some interest that, in two or three of the plants examined, isolated tracheides were found in the central phloem, thus emphasizing the essentially vascular nature of the cauline strand as a whole at this level (Fig. 202). The first leaf- and root-traces are formed at approximately the same level, separated by about $100^{\circ}$.

The leaf-trace is of the normal concentric type, the xylem being a slightly curved band, and the shallow gap, which is occupied by the phloem of the pith, is merely bridged by the endodermis. The leaf-gap is hardly closed (in one or two cases it was actually not closed) when the next leaftrace is formed exactly opposite the last, accompanied by two roots. The usual occurrence of a single root for each leaf does not seem to hold in 
the case of Nephrodium setigerum, all the plants examined showing the roots to be more numerous, and somewhat irregularly arranged.

The first few leaf-traces are formed in a manner similar to that described above, the closing of the gaps resulting in the formation of a ring of xylem surrounded by phloem, and containing a phloem pith in which isolated tracheides occasionally occur. After about the fifth or sixth trace, a portion of the xylem ring becomes reduced in thickness to only two or three rows of tracheides, the attenuated arc bulging slightly outwards. At a higher level, this arc of vascular tissue passes out as a leaf-trace, but before the xylem has broken away from the cauline strand we have the formation of so typical a fundamental-tissue pocket that no further description is necessary. A transverse section of the stem through the region of the pocket is shown in Fig. 203. The leaf-trace presents a distinctly bilobed appearance, especially with regard to its xylem, and, as might be expected, this is an indication of the later formation of multiple leafstrands. Before the gap closes, the cauline strand becomes strongly curved, the middle portion of the arc being thinner than the extremities, and quickly passing out as a leaf-trace which is still more markedly bilobed than its predecessor.

The subsequent closing of the previous gap is followed by a resplitting of the strand into two unequal parts. The next leaf-trace is joined to the margin of this split, and is double from its origin. The subsequent elaboration of the vascular system results in the formation of the usual dictyostelic structure, and need be described at no further length.

The young plants of Nephrodium setigerum would be described as 'soft' plants by the cultivator, sclerenchyma being absent in the groundtissue, a state of affairs very different from that obtaining in other ferns, e. g. Pteris palmata. The endodermis is well marked, but its cells are by no means in perfect seriation with those of the pericycle, which generally consists of but one layer of cells without the very abundant contents which so often characterize this layer. The vascular-tissue elements call for no special description except that the small sieve-tubes are well differentiated, and that the xylem contains a considerable amount of parenchyma, which frequently occurs as plates of cells in connexion with thełphloem.

\section{NEPHRODIUM HIRTIPES, Hk.}

The early transitional changes of Nephrodium hirtipes proved to be of quite an interesting character. Unfortunately, the writer was unable to verify his results in more than the five plants at his disposal, but the essential uniformity of the few examples investigated affords good reason for supposing that the phenomena observed are those obtaining generally in the plant. 
The root is of the usual diarch character, and the passage to the protostele is of the normal type. One or two parenchyma cells appear in the xylem, but do not form a central core as is usually the case. Sievetubes are not differentiated. The xylem does not long retain its rod-like character, but quickly becomes irregularly angled as seen in transverse section (Fig. 37); protoxylem elements are not distinguishable at this stage. At a higher level, the irregularities have largely disappeared, and the vascular tissue is in the form of a slightly curved band with somewhat sharply pointed horns (Fig. $3^{8}$ ). As soon as the vascular strand has reached this condition, the first leaf-trace is differentiated in a manner remarkably different from that occurring in other ferns. From each of the sharp horns of the arc a concentric strand is constricted off, the two strands gradually passing outwards. The distance between them is maintained until just before the base of the petiole is reached, when they suddenly unite, entering the petiole as a single concentric rod.

The early appearance of such a double leaf-trace is very different from the usual state of affairs, the more so as it appears spontaneously, as it were, without any intermediate stages being passed through. Again, the method of formation of the trace is very unusual, reminding one of the simple process obtaining in Polypodium aureum (q. v.). During the exit of the trace, the vascular arc becomes attenuated at its middle, the ground-tissue ' encroaching upon' it at this point to such an extent that, on the completion of the leaf-trace, the cauline system consists of two separate concentric strands (Figs. 39, 40). One of the strands quickly divides into two parts (Fig. 4I), but later the three strands thus formed unite into a band of vascular tissue, which at a higher level becomes broad and sharply bent (Figs. 42-44). Fig. 45 shows in ground-plan the differentiation of the next leaf-trace. It is formed in the same way as its predecessor, and like the latter enters the leaf-stalk as a single strand. One of the leaf-strands separates from the cauline system at a slightly lower level than the other (Figs. 44, 45).

Subsequent changes are very interesting in relation to what has gone before, since the third leaf-trace, instead of being double like those preceding it, is single at its origin, although the xylem is slightly bilobed; indeed, the double and, in some cases, multiple character of the later-formed leaf-traces is only arrived at after the preceding traces, from the third onwards, have passed through the usual progressive stages of complexity, starting with a petiolar bundle in which the xylem is merely bilobed, and ending with a leaf-trace composed of two or more separate concentric strands, each surrounded by a pericycle and endodermis. The chief stages in the process are as follows:-After the exit of the second trace, the vascular band enlarges slightly, and its central portion passes out as the third leaf-trace; the xylem of the latter is, as mentioned above, distinctly bilobed. After the differentiation of the third trace, one of the cauline 
strands divides into two (Fig. 47) and the subsequent union at a higher level, indicated in Fig. 48, takes place. The fourth leaf-trace is double at its origin (Fig. 49), but before it enters the leaf-stalk the two strands have united. In Fig. 50 we have three cauline strands, and at higher levels in older plants several appear in a transverse section of the stem. The increase in number is, of course, due to the division of the vascular strands before the previous leaf-gap has been repaired, and the repetition of such a process results in the dictyostelic arrangement of the vascular system of adult plants being attained.

The leaf-traces maintain their double character for successively longer periods, with the final result that the petioles of the later leaves possess two or more strands.

Nephrodium hirtipes has previously been examined by Jeffrey, and referred to by that author in his Royal Society memoir ${ }^{1}$. The details of the vascular development, however, were not described.

\section{ASPlenium NidUs, L.}

The vascular strand of the young primary root is extremely small, consisting of but a few sieve-tubes arranged on either side of a minute xylem plate. The first leaf-trace is given off quite early, before the xylem has lost its diarch character, and is quickly followed by a root-trace. The leaf-trace arises merely as a nipping off of one of the protoxylem groups, and is formed in a manner very similar to that obtaining in Polypodium aureum. As is so generally the case, the first few leaf-traces are of simple structure, consisting of two or three tracheides surrounded by a single layer of poorly differentiated sieve-tubes. The corresponding root-traces are much more definite, the well-marked endodermis being particularly conspicuous when the rootlets are viewed transversely.

A certain amount of variation was met with in the early transitional region. In a few cases, the first two or three leaf-traces were formed before a central pith of phloem had appeared in the xylem strand (cf. Todea Fraseri ${ }^{2}$, Lygodium ${ }^{3}$, and Angiopteris ${ }^{4}$ ), but, generally, parenchyma cells and extremely well-marked sieve-tubes were differentiated at the centre of the xylem immediately after the first leaf-trace. Higher up the stem the central phloem increases in quantity, and after the second leaf-gap has closed in the usual manner, a transverse section of the stem presents the appearance found to be so common in the other plants investigated, viz., a ring of xylem surrounded by phloem, and enclosing a strand of phloem

1 Jeffrey, Structure and development of the stem in the Pteridophyta and Gymnosperms. Phil. Trans., ser. B., cxcv, 1902, p. I31.

${ }^{2}$ q. v. $\quad 3$ Boodle, Schizaeaceae. Annals of Botany, xv.

4 Farmer and Hill, On the arrangement of the vascular strands in Angiopteris evecta. Annals of Botany, xvi. 
in which the sieve-tubes take up a central position. The pericycle is composed of relatively large cells, and is succeeded by an obvious but not particularly well-differentiated endodermis.

The third and fourth leaf-traces are formed in the same manner as the second, the external and internal phloem becoming continuous at the gaps, which are merely bridged by the endodermis. The pericycle gradually becomes two or three layers in thickness. After the exit of about the fourth trace, preparations are made for the change of the leaf-strand from a single to a double character. The change is effected in the usual way, viz., by the breaking of the curved xylem band into two before the closure of the previous gap, followed by a nipping off of a concentric strand from each of the vascular horns so formed. The two leaf-strands, however, unite immediately they leave the cauline system, so that the actual trace is single as before. At the level of the fifth or sixth leaf-trace we have the differentiation of a ground-tissue pocket of the usual type, a single cell, often containing tannin or mucilage, and surrounded by a well-marked endodermis, appearing in the central phloem. A little higher up, this internal endodermis surrounds a small group of ground-parenchyma cells, which become continuous with the main mass of ground-tissue at the next leaf-gap. At other times the endodermis appears immediately after the exit of a leaf-trace, and becomes continuous with the outer layer before the corresponding gap has been closed. In both cases the net result is the same, viz., the separation of the cauline vascular system into two concentric strands each surrounded by an endodermis (Fig. 82).

Later changes are represented in the diagrams. One of the two cauline strands divides into two parts for the insertion of the double leaf-trace, and one part immediately joins with the other main cauline strand, thus closing the previous leaf-gap. The vascular system still consists, therefore, of two concentric strands (Figs. 83, 84). The leaf-trace is then given off; as before, it is double at its origin, but enters the leaf as a single vascular rod. Figs. 86-88 illustrate the closing of the previous gap and the differentiation of the next leaf-trace. At the level of about the ninth leaf, the splitting of the cauline strand and the subsequent formation of the trace takes place before the closure of the previous gap, i. e. the gaps 'overlap,' and we consequently have the appearance of three cauline strands (Figs. 89, 90).

Subsequent elaboration need be described in no great detail. By the repeated overlapping of the gaps, the number of cauline strands at succeeding levels is gradually increased, and the dictyostelic structure of the mature plant is soon reached. From about the eighth leaf onwards, the two strands of the leaf-trace remain separate through increasingly longer intervals until they enter the petiole as two, or in the later leaves, more than two, separate strands. 


\section{Aspidium falcatum, Sw.}

The young plants are characterized by the total absence of sclerenchymatous ground-tissue, even in the rootlets. The transition from the diarch root to the protostele extends over a considerable distance, and, as in Nephrodium setigerum, the completion of the phloem sheath is delayed for some time. The xylem of the protostele forms a very small rod of tissue, at the centre of which parenchyma cells are differentiated, quickly succeeded by very obvious sieve-tubes.

The first lateral rootlet generally effects its junction with the stem just before the exit of the first leaf-trace, which is formed in a perfectly normal manner, leaving a small gap bridged by the endodermis. In examining a large number of seedlings, some little variation was observed in connexion with the formation of this leaf-trace, a variation occurring more than once being represented in Figs. $129-132$. It will be seen that the xylem ring has opened, and that from one horn a concentric strand of vascular tissue is nipped off which passes outwards as the leaf-trace. In the majority of cases, however, the trace was perfectly normal, and on repair of the gap a ring of xylem enclosing and enclosed by phloem constituted the cauline strand.

The second and third leaf-traces are formed in rapid succession nearly opposite one another, the gaps closing almost immediately. Their exit is followed by a long internode, and then another pair of leaf-strands is differentiated. This regular alternation of long and short internodes held true for all the comparatively young plants examined.

In connexion with the fifth trace we have the appearance of a groundtissue pocket. The internal sieve-tubes arrange themselves towards the periphery of the internal phloem and therefore lining the xylem, and in the central parenchyma a poorly differentiated patch of endodermal cells appears, which, a little distance above, surrounds a strand of ground-tissue, the latter becoming continuous at the leaf-gap with the main mass of fundamental parenchyma. After the completion of the trace, another leaf-strand is formed exactly opposite the last, and the cauline system then consists of two strands which finally fuse.

Unfortunately, older plants were not available, but the above phenomena are so similar to those described for other types that there can be little doubt that the subsequent fractionation of the vascular tissue takes place in a manner similar to that already described.

\section{Pteris palmata, Willd.}

The transitional changes are of the usual type. The root is diarch, the xylem plate rapidly becoming circular in section and surrounded by the phloem. The appearance of phloem in the protostele takes place 
before the first leaf-trace. The first two leaf-strands are quite simple, and the resulting gaps are merely bridged by the endodermis. At about the third leaf-trace a fundamental-tissue pocket appears in the central phloem in a way almost identical with that described above for other ferns. A patch of endodermal cells appears, quickly followed at a higher level by an endodermis surrounding a patch of ground-parenchyma cells containing tannin. The inner endodermis becomes continuous with the outer at the succeeding leaf-gap, and the subsequent elaborative changes of the vascular system are essentially the same as in the case of other ferns with similar fundamental-tissue pockets.

The most striking character in the anatomy of this plant is the abnormal width of the pericycle. The excessive width results not only from the treble, and sometimes quadruple nature of the layer, but also from the large size of the cells themselves. The latter are densely crowded with starch, and are not arranged in radial rows. The ground-tissue in young plants, or in the lower parts of older ones, is in striking contrast with the thin-walled pericycle. It is wholly composed of cells with thick, brown, sclerotic walls, even the outer tangential walls of the endodermis being strongly sclerosed; higher up the plant, however, a thin-walled band of ground-tissue separates the vascular strand from the outer sclerotic portion. It will be remembered that an exactly similar state of affairs occurs in Osmunda, and also in Lygodium, as described by Boodle.

\section{TODEA Fraseri, H. and G.}

By the kindness of Mr. Boodle the writer had the opportunity of examining seedlings of two species of Todea, viz. T. hymenophylloides and T. Fraseri. Examination of the former fully confirmed the account of the transitional region given by Seward and Ford ${ }^{1}$, who found in this fern an essential agreement with the transitional changes occurring in Osmunda regalis (Leclerc du Sablon).

The changes occurring in $T$. Fraseri closely resemble those of $T$. hymenophylloides. The root possesses a very simple vascular strand, the xylem being diarch and consisting of but a few tracheides. The sievetubes are somewhat ill-defined, as is also the endodermis. The ground-tissue is highly scelerotic. The usual change of the xylem plate to a solid strand occurs, and the first leaf-trace is formed while the xylem of the protostele is still very small in amount, consisting of about six or seven tracheides. No leaf-gap is formed, a few tracheides surrounded by phloem being merely nipped off from the stem strand. After the first trace, the xylem increases in quantity, and the sieve-tubes become much more prominent. The endodermis is very indistinct, and readily torn in the process of cutting; in

1 The anatomy of Todea. Trans. Linn, Soc., 2nd ser., vol, vi, 1903. 
favourable sections, however, it was seen that its cells were not in seriation with the pericycle cells, thus confirming a similar statement made by Seward and Ford with regard to $T$. hymenophylloides.

\section{Dicksonia AnTARCTiCA, Labill.}

The development of the vascular system in Cyatheaceae has received but little attention. As far as the writer is aware, the only account of the transitional changes is that occurring in Gwynne-Vaughan's second paper on Solenostelic Ferns ${ }^{1}$, in which the author describes the young stages of Alsophila excelsa. In addition to the latter plant, the writer has had the opportunity of examining Dicksonia antarctica.

The vascular strand of the primary root is of the normal diarch type, resembling that of Alsophila excelsa in being extremely small. The vascular elements, however, especially the sieve-tubes, are well differentiated. The usual transition to the solid protostele occurs, and a single parenchyma cell, quickly followed by two or three others, is differentiated in the xylem rod. In the majority of the plants examined this parenchyma strand occupied a markedly excentric position, the appearance presented by this isolated section reminding one of the normal structure of Lindsaya. The excentric position in Dicksonia, however, is evidently merely connected with the exit of the first leaf-trace, which is concentric in structure, and formed in a perfectly simple manner. It will be noticed that no sievetubes appear in the central parenchyma before the exit of the first trace, a state of affairs differing from that obtaining in Alsophila. In one case, however, a well-marked sieve-tube was observed in the parenchyma between the cauline strand and the outgoing leaf-trace, and this point, in conjunction with the fact that only four specimens of this fern were available for examination, would seem to indicate that, in all probability, internal phloem is differentiated before the first leaf-trace, just as described for Alsophila.

At the exit of the trace, phloem appears on the inner surface of the vascular arc, and, after the closing of the gap, we have a ring of xylem enclosing a strand of phloem, largely parenchymatous, and surrounded by a phloem sheath in which the narrow deeply-staining sieve-tubes are very conspicuous. At this level a considerable amount of parenchyma occurs in the xylem, often so arranged as to break the xylem ring into two or three arcs. The ring-like character of the vascular tissue as a whole, however, is perfectly obvious.

The vascular ring then becomes strongly elliptical in outline, receiving a root-trace at one end of the ellipse. The next leaf-trace is formed exactly opposite the root, its gap closing somewhat abruptly. During

1 Observations on the anatomy of Solenostelic Ferns, II. Annals of Botany, xvii. 
these changes the vascular tissue has increased greatly in size, the xylem, as before, being still somewhat parenchymatous. The next leaf-trace is very quickly formed, exactly opposite the last; the corresponding gap soon closes, and the following leaf-strand shows distinct indications of a double character which no doubt obtains in later leaf-traces. The repair of this gap results in the completion of the vascular ring, a condition which is maintained unaltered for some little distance. In connexion with the next leaf-trace, however, we have, just as in Alsophila, the formation of a typical ground-tissue pocket, the apex of the pocket in this case being blunt, and occupying a considerable portion of the central phloem. The actual course of events is as follows:-Several cells, some eight or nine in number, and possessing thickened refractive walls, appear at the centre of the phloem and persist through four or five sections. These cells are no doubt endodermal in function, and are succeeded by a patch of parenchymatous cells resembling those of the ground-tissue and surrounded by a definite endodermis, an isolated section presenting a ' gamostelic' appearance. As in similar cases described, the inner and outer endodermis become continuous at the gap, and the pocket-like character of the central ground-parenchyma is demonstrated.

Unfortunately, no older plants were available for examination. The great similarity between the above early transitional changes and those described as occurring in the young plant of Alsophila, leaves little doubt that subsequent changes in Dicksonia are essentially the same as those given in the excellent account of Gwynne-Vaughan.

\section{Conclusions.}

A discussion of the results arrived at in the above research involves a consideration of the stelar question. It would be serving no useful purpose, however, to follow in detail the various changes of thought which have followed upon the enunciation of Van Tieghem's famous hypothesis, since the history of the question is of general knowledge, largely owing to the appearance, from time to time, of excellent résumés of the subject, prominent among which are those of Tansley ${ }^{1}$, Faull ${ }^{2}$, and Schoute ${ }^{3}$.

At the present time, botanists are practically unanimous in regarding Van Tieghem's conception of polystely as no longer affording a real explanation of observed facts. His work fails chiefly because the investigation of individual types was not carried far enough, for there can be little doubt that, had Van Tieghem followed out the complete elaboration of the

1 The Stelar Theory. Science Progress, I 896.

2 The anatomy of the Osmundaceae. Botanical Gazette, xxxii.

3 Die Stelär-Theorie. Groningen, 1902. 
vascular system of an ordinary 'polystelic' type, the idea of a continuously branching protostele would never have been formulated. Van Tieghem's work was essentially an attempt to reduce to some common plan the various existing arrangements of vascular tissue, and as such deserved, and received, the greatest attention. That it has since been shown to be partially incorrect ${ }^{1}$ in no way alters the fact that it has secured the greatest reward which can fall to the work of a pioneer, viz., the stimulation of investigation.

In 1897 Gwynne-Vaughan ${ }^{2}$ published his well-known paper on Polystely in the genus Primula, in which it was conclusively shown that the idea of polystely, as advanced by Van Tieghem, must be given up for this genus, since the polystelic arrangement does not follow from the branching of an originally single vascular rod, but as a result of repeated perforations of a vascular tube by gaps occurring in connexion with the leaf-traces. This idea was elaborated and extended by Jeffrey in his memoirs of $1897^{3}$, $1900{ }^{4}$, and $1902^{5}$. According to this writer, there are two types of cauline central cylinder : the first, a solid xylem rod surrounded by phloem (protostele), and the second, the siphonostele, a ring or tube of xylem surrounded externally and internally by phloem and endodermis, the whole vascular tube being sheathed externally by the cortex, and enclosing a central medulla or pith ${ }^{6}$. Of these two types the protostele is regarded as the more primitive. The presence of an internal endodermis separating the vascular tissue from a non-' stelar' pith is an essential point of the theory. As is so well known, the interruption of this vascular tube by the exit of the leaf-traces, followed later in life by an elaborate overlapping of the foliar gaps, results in the polystelic, or preferably dictyostelic ${ }^{7}$, type so characteristic of the ferns.

This is the view which meets with very general acceptance at the present day, and the readiness with which its author has extended it to all the great classes of vascular plants makes it all the more convincing. That, however, the theory is not entirely satisfactory is evidenced by the fact that from time to time other views have been put forward, which, although essentially based upon the conception of Jeffrey, nevertheless differ sufficiently from it as to warrant full consideration.

The first of these is that put forward by Boodle ${ }^{8}$ in his series of papers on fern anatomy. This view, defined as briefly as possible, appears to be that the whole ring of vascular strands as seen in a transverse section of the stem of a dictyostelic leptosporangiate fern, together with the mass of parenchyma included within the ring, corresponds to, or is homologous with, Van Tieghem's medullated monostele. It follows that the 'pith'

1 Cf. opinion of Schoute, loc. cit.

2 Polystely in the genus Primula. Annals of Botany, xi.

3 Trans. Brit. Assn., Toronto, I897.

5 Phil. Trans., 1902.

${ }^{7}$ Cf. Brebner, loc. cit.

4 Trans. Canad. Inst., I900.

${ }^{6}$ Cf. Faull, loc. cit.

${ }^{8}$ Schizaeaceae. Annals of Botany, xv, p. 404 et seq. 
parenchyma is wholly distinct from the external or cortical parenchyma. In the light, however, of Gwynne-Vaughan's and Jeffrey's work, this view is, to many, somewhat difficult of acceptance. The weak point in the conception is the implied distinction drawn between the parenchyma outside and the parenchyma inside the ring of vascular strands. There seems to be no reason why any such distinction should be drawn between tissues which are shown by a study of the young plant to be part and parcel of one and the same thing, viz., the general ground-tissue.

The next view is that of Farmer and $\mathrm{Hill}^{1}$ as put forward in their paper on Angiopteris evecta. Acknowledging the importance of Jeffrey's work in bringing the vascular system as a whole to the fore in all 'stelar' questions, the authors point out that the weakness of Jeffrey's theory is the retention of the endodermis as an indispensable constituent of the primitive siphonostele. As a result of their work on the Marattiaceae, and from the evidence afforded by Helminthostachys, Botrychium, and Osmunda as to the unreliability of the endodermis as a morphological criterion, the authors maintain that in dealing with all so-called stelar questions, tissues of two categories only need to be considered, viz., vascular and non-vascular.

Schoute, in his memoir already quoted, deals with the question in a very exhaustive manner. Not the least important service rendered by the author in this valuable essay, is his emphasizing a fact which is very apt to be overlooked, viz., that the results of modern research after all only confirm the main contention of Van Tieghem that the monostele is the primary structure in all vascular plants. This author, however, criticizes Van Tieghem's stelar theory from two points of view; firstly, from a study of the development of the plant, both from the embryo and from the growing point of the adult, and, secondly, from the point of view of comparative anatomy. As a final result of his work, Schoute concludes that 'in Stengel und Wurzel der Gefässpflanzen findet sich ein einziger Stelär-Typus, die Monostelie.'

Having thus briefly outlined the present position of the stelar question, the writer may perhaps be allowed to consider the bearing, if any, which the results of his investigations have upon the question.

The simplest type of vascular elaboration above described is (with the exception of Polypodium aureum) that of such a fern as Doodia aspera. It will be remembered that the primary condition of the vascular system is a solid vascular rod, which later appears with a central strand of tissue which is undoubtedly phloem. The differentiation of this central phloem in no way alters the essential character of the young cauline strand, which is that of a solid rod of vascular, as opposed to non-vascular, tissue. Following upon the appearance of the central phloem we have the formation of several leaf-traces which leave no real gaps in the ordinary sense of the 
word, the external phloem becoming continuous with the internal at each exit of a trace, and the endodermis merely stretching between the horns of the temporarily broken rod. It will be noticed that there is no question of a primitive xylem rod with a central strand of ' extra-stelar' parenchyma ; still less is there any evidence of an internal endodermis. We merely have an amphiphloic vascular rod to which are attached, in the simplest manner, the vascular bundles which supply the leaves. Subsequent processes are merely an elaboration of this primitive strand, the resulting structure no doubt representing the most satisfactory compromise in meeting the requirements of several demands, prominent among which is the necessity for an efficient mechanical distribution of the tissues concerned. The steps by which the mature condition of the vascular tissue is reached are very simple.

At about the fourth or fifth leaf-trace, the gap is no longer very small, but of such a size that ground-tissue is differentiated between the horns of the gap, the ground-parenchyma everywhere being separated from the vascular tissue by the endodermis. Before the gap is closed, the vascular arc breaks at a point opposite it, and, from each of the two horns, a strand is nipped off, the two forming the first double leaf-trace. Soon afterwards, the first gap closes and is followed by a re-splitting for the next trace. In older plants, the overlapping of the gaps is the most striking feature, and a simple type of dictyostely is attained without the previous appearance of Jeffrey's siphonostele, consisting of an amphiphloic vascular ring with an internal and external endodermis.

Although the vascular system of Doodia aspera is undoubtedly the simplest type examined, the writer is of opinion that it does not represent the true phylogenetic development of the vascular system of the Polypodiaceae. It is best considered as a simplification of that other type of vascular elaboration which was found to be so general among the plants investigated, viz., that in which an early appearance of a ground-tissue pocket was a characteristic feature. It will be remembered that the appearance of the first ground-tissue pocket usually occurs at that region of the plant at which the leaf-traces show a transition from the single to the double character. This transition is not met with in Doodia aspera, and, further, the first double leaf-trace appears relatively early in this plant, supplying as it does the fifth leaf, whereas in the majority of other forms examined it did not appear until the level of the sixth or seventh leaf. That is to say, the stage at which, from the study of other forms, we should expect to meet with a ground-tissue pocket is omitted in this plant. To put the matter briefly, the type of vascular elaboration met with in Doodia aspera is probably best regarded as a 'short cut' to the adult dictyostelic arrangement. In the type exhibiting a ground-tissue pocket, the protostele, as usual, soon gives way to a ring of xylem surrounding and surrounded 


\section{Chandler.-On the Arrangement of the Vascular Strands}

by phloem; the early leaf-traces are quite simple, and then suddenly in the central phloem we have the appearance, in surface view, of one or two endodermal cells, followed immediately by definite ground-tissue cells surrounded by a ring of elements possessing all the well-known characters of an endodermis. These phenomena may possibly be interpreted as meeting the demands of the plant for a more peripheral arrangement of its vascular tissues than has obtained hitherto, the demand being met by the differentiation, from the meristem, of a central cone of ground-tissue continuous with the general mass of ground-tissue, and with its apex pointing downwards. Certainly a most striking fact in connexion with this groundtissue pocket is that the fundamental-parenchyma is at all points shut off from the vascular tissue by a continuous sheath of endodermal cells. It is quite unnecessary to describe the further changes resulting in the perfection of the mature dictyostelic structure, since they have been given in full elsewhere. The interest of these plants lies in the fact that, at a level immediately succeeding the appearance of the internal endodermis, we have a very transitory condition of affairs exactly resembling, in an isolated section, the structure of the primitive siphonostele demanded by Jeffrey's hypothesis (Fig. 20I).

In the light of what has been previously said as to the origin of this ground-tissue pocket, its essential structure, and its relationship to the general mass of ground-tissue, the writer believes that the assignment of a morphological significance of fundamental importance to such an arrangement of tissues is, perhaps, unjustifiable. The reason for the appearance of the internal ground-tissue appears to be fairly obvious, if, with Jeffrey, we admit the important part which mechanical considerations must play in the elaboration of the vascular system. The plant, at the time when the pocket is differentiated, apparently requires a more peripheral arrangement of its vascular tissues, and the dilatation of the existing conducting-tissue is probably the least expensive and most efficient means of meeting the requirements of the case. Before the necessity for such dilatation arises, the vascular strand is amphiphloic in structure, and since the separation of vascular from non-vascular tissue is so very generally effected by the presence of an endodermal sheath, the differentiation of internal groundtissue naturally results in the appearance of an amphiphloic and amphiendodermic vascular ring to which it is unnecessary, perhaps, to ascribe any profound significance.

The position, therefore, which the writer is inclined to take up with regard to the evolution of the dictyostelic vascular system is that the latter is derived from a certain simple primitive type, as a result of meeting the demands of several requirements, the chief and most obvious of which are, (1) the efficient distribution of the vascular tissue, (2) the increase of the conducting system in the young plant. The primitive type is not regarded 
as being a solid rod of xylem surrounded by phloem, and later an amphiphloic tube with an inner endodermis surrounding non-stelar tissue, but as a solid strand of vascular tissue which may be either a solid rod of xylem ensheathed by phloem (protostele), or a ring of xylem surrounded by, and surrounding, phloem (amphiphloic protostele).

It may be objected that at the very base of the young stem a few parenchyma cells are differentiated at the centre of the xylem immediately before the appearance of internal sieve-tubes, and that such parenchyma cannot be regarded as vascular tissue. Definite internal phloem is so quickly differentiated, however, that there can be little doubt that the parenchyma cells, which are in organic continuity with the internal phloem, are best regarded as potential phloem. The wholly vascular nature of the cauline strand at this level is further emphasized by the occasional differentiation of tracheides in the internal phloem, an example occurring in Nephrodium setigerum being illustrated in Fig. 202.

The insertion of the leaf-traces upon this primitive strand has resulted in the latter becoming moulded and modified along certain definite lines, the culminating structure being the dictyostelic complex. In all probability this arrangement of the vascular tissues is the most satisfactory for allowing an adequate supply of water and mineral food to reach the relatively large leaves. The portion of the cauline system actually in connexion with the leaf-strands is probably quite insufficient to afford this supply, and the latter is only effected as a result of the ready transference of water from one part of the rhizome to another, which is rendered possible by the complete network of the vascular strands.

It has been stated above that the ontogenetic elaboration of the vascular system proceeds along certain constant and well-defined lines. As has been shown by Boodle and others, not the least interesting point in connexion with this fact is that many of the admittedly more primitive ferns have proceeded for only a relatively short distance along these ontogenetic and, presumably, phylogenetic lines. The elaboration of their vascular system stops short, as it were, at some intermediate stage or condition which is adopted by the plant as the most suitable for its mature habit. Take, for example, a typical dictyostelic fern such as Blechnum brasiliense. The first stage is the solid protostele, a structure adopted as the mature organization by Lygodium. The appearance of central parenchyma follows, a condition which is exactly matched in Schizaea. Later, well-defined sieve-tubes appear in the central parenchyma, and this structure, although rare in mature plants, is found in Lindsaya ${ }^{\text {. }}$ The region at which we have the differentiation of the ground-tissue pocket is the most interesting in the whole series of elaborative processes. If we imagine this conical pocket continued through successive internodes (cases

\footnotetext{
1 Tansley and Lulham, loc. cit.
} 
in which it was continued through two internodes were noted above), then we have a condition of affairs resembling in all essential points the mature structure of ferns described by Gwynne-Vaughan as solenostelic ${ }^{1}$. That such solenostelic vascular systems have passed through the previously described ontogenetic conditions has been shown by Gwynne-Vaughan in Alsophila, and by the writer in Dicksonia. From the solenostelic to the dictyostelic type the changes are rapid and obvious. They merely depend upon the rates at which the leaf-gaps overlap one another, and the final result is the formation of a vascular network of the type familiar to every one.

A group of plants very interesting in this connexion is the Osmundaceae. De Bary ${ }^{2}$ and Van Tieghem both recognized the striking difference of the vascular organization from the ordinary leptosporangiate type, and the latter author, from a study of seedlings, maintains that the plant in question possesses, as in the case of Phanerogams, a medullated monostele. The Osmundaceae have also received the attention of Leclerc du Sablon ${ }^{3}$, and later of Zenetti ${ }^{4}$, Faull ${ }^{5}$, and Seward and Ford ${ }^{6}$.

The work of Faull is of especial interest, since a type of vascular system new to the Osmundaceae was discovered in Osmunda cinnamomea. This plant, it will be remembered, possesses an internal endodermis; internal phloem, however, is absent, except occasionally at the ramular gaps. The internal endodermis, moreover, is sometimes continuous with the external endodermis through the foliar gaps, and generally so through the ramular gaps. It follows that at such regions the parenchyma surrounded by the internal endodermis, and the external ground-parenchyma, are put into continuity. The author concludes that the internal and external parenchyma are morphologically identical, and from this conclusion there can, perhaps, be little question of dissent ; but the contention that the vascular system of $O$. cinnamomea represents a degenerate siphonostelic type is not so convincing. The present writer fully agrees with the criticism of Boodle ${ }^{7}$, that the great weakness of Faull's position results from a neglect, no doubt compulsory, of the ontogeny of the vascular system of the plant concerned. In fact, the whole question depends upon how and when the internal endodermis with its included ground-parenchyma arises, and this can only be settled by a study of young plants. The writer believes that such a study will show that the internal endodermis arises as a necessary accompaniment of a typical ground-tissue pocket, similar to those described above, and differentiated early in the life of the plant. This pocket has, in all probability,

1 Observations on the anatomy of the Solenostelic Ferns, Annals of Botany, xv.

2 Loc. cit., p. 3 I9.

3 Loc. cit.

- Das Leitungssystem in Stamm von Osmunda regalis. Bot. Zeit., 1895 .

5 Loc. cit.

6 Loc. cit.

7 Further observations on Schizaea. Annals of Botany, xvii. 
'persisted' through successive internodes, and is only occasionally in continuity with the external ground-tissue at the gaps. That is to say, the structure occurring in $O$. cinnamomea is very closely akin to that of solenostelic ferns, the absence of internal phloem being the chief difference, while the resemblance to Platyzoma microphyllum ${ }^{1}$ is even more striking.

If the above contention should ultimately prove correct, it would have an important bearing upon the relative primitiveness of the different types of vascular organization occurring in the Osmundaceae. Faull believes that $O$. cinnamomea and $O$. Claytoniana stand at opposite ends of a series, with $O$. regalis as an intermediate form. Strictly speaking, there is no essential difference between the vascular systems of $O$. regalis and $O$. Claytoniana, and hence, for the purpose of comparison, they may be regarded as the same. Of this series Faull regards $O$. cinnamomea as the more primitive, i. e. least modified from the amphiphloic siphonostelic type, and derived from the siphonostele by 'degeneration.' From this it follows that $O$. regalis and $O$. Claytoniana have still further degenerated.

This position has already been subjected to criticism at the hands of Boodle, and, as a result of the present work, the writer is inclined to take a diametrically opposite view of the question. Admitting that a complete knowledge of the young vascular system in the Osmundaceae is urgently needed, he believes that comparison with other and fully-known types points to the conclusion that the type of vascular organization possessed by $O$. regalis and $O$. Claytoniana is that which is more primitive, and that the vascular system of $O$. cinnamomea, instead of being the result of degeneration, is, so to speak, really on the up-grade, and has, indeed, advanced a considerable distance along the phylogenetic road which at the present time leads to dictyostely.

The structure of $O$. regalis and $O$. Claytoniana can be plausibly explained if compared with the young vascular system of a Polypodiaceous fern. The earlier leaf-traces of the latter involve the differentiation of no real leaf-gaps-we have merely the xylem discontinuous at a certain point, and the external and internal phloem more or less continuous between the horns of the xylem. Now, if we consider a plant in which the internal potential vascular tissue does not assume the definite characters of phloem (and this is merely assuming the persistence of the earliest condition of a dictyostelic vascular system) ${ }^{2}$, then this first 'leaf-gap' corresponds to a 'medullary ray' of Osmunda. If, further, we suppose the first and succeeding leaf-gaps to remain unclosed, we have a structure exactly resembling that found in mature plants of Osmunda

1 Boodle, Comparative anatomy of the Hymenophyllaceae, Schizaeaceae, and Gleicheniaceae. III. Gleicheniaceae. Annals of Botany, xv.

${ }^{2}$ Cf. Angiopteris evecta. 
regalis, and it follows that the pith of this species must be regarded as belonging to the central cylinder, as maintained by Van Tieghem. On the other hand, Faull's work clearly shows that the pith of $O$. cinnamomea is extra-stelar in nature. Consequently we must regard the pith in these two members of the same genus as of different morphological value, and the vascular arrangements in the two cases as fundamentally distinct. To some, the acceptance of this view would be a matter of difficulty, but it is by no means impossible to find a parallel, an almost equally striking difference in the arrangement of the vascular tissues occurring in the genus Anemia, where, in A. mexicana we have a solenostelic vascular system, in $A$. Phyllitidis a typical dictyostelic arrangement, and in $A$. aurita an arrangement closely approximating to that of Lygodium. If the validity of the above interpretation of the vascular systems of Osmunda regalis and $O$. cinnamomea be admitted, then it follows that the vascular organization of $O$. regalis is the more primitive, and that the type occurring in $O$. cinnamomea is less so.

The vascular organization of $O$. cinnamomea, therefore, may be regarded as having been evolved in two alternative ways; either as a result of degeneration from a typical siphonostelic structure, or, on the other hand, it may represent an intermediate halt on the direct line of advance to dictyostely. For reasons already given, the writer is inclined to regard the latter view as the more probable.

To sum up. As a result of the study of certain leptosporangiate ferns, the writer has been led to conclude that:-

(a) in dealing with questions of a so-called stelar character, we must confine our attention to tissues of two categories only, viz., vascular and non-vascular;

(b) the primitive type of vascular system in the ferns is a solid rod of vascular tissue, which may be a solid xylem strand surrounded by phloem, or an amphiphloic strand;

(c) the complex dictyostelic structure results from the moulding and elaboration of this solid vascular strand, the moulding and elaboration being largely due to the necessity for an efficient attachment of the leaftraces ;

(d) the differentiation of ground-tissue pockets plays an important part in such elaboration;

(e) the development of the vascular system proceeds along certain well-defined lines, and that practically all the intermediate stages have been adopted by different plants as most suited to their individual mature requirements;

$(f)$ the ontogeny of the vascular system strikingly resembles what we must suppose to have been its phylogeny. 


\section{in the 'Secdlings' of Certain Leptosporangiate Ferns. 409}

It would be impossible for the writer to conclude without expressing his grateful thanks to Professor J. B. Farmer, F.R.S., for the continuous interest he has taken in the above investigation. The work was carried out at the suggestion of Professor Farmer, and but for his kindness in allowing the writer the use of a table in his laboratory, the research would have been impossible.

\section{Alphabetical List of Ferns Examined.}

Aspidium falcatum, Sw.

Aspidium Tsus-Simense, Hk.

Asplenium bulbiferum, Forst.

Asplenium nidus, $\mathrm{L}$.

Blechnum brasiliense, Desv.

Dicksonia antarctica, Labill.

Doodia aspera, R. Br.

Lomaria gibba, Labill.

Lomaria Spicant, Desv.
Nephrodium hirtipes, Hk.

Nephrodium setigerum, Baker.

Nephrodium spinulosum, var. dilatatum, $\mathrm{Hk}$.

Nephrolepis cordifolia, Baker.

Nothochlaena sinuata, Kaulf.

Polypodium aureum, $\mathrm{L}$.

Pteris palmata, Willd.

Todea Fraseri, H. and G.

\section{LIST OF WORKS REFERRED TO.}

Boodle. (I) Comparative anatomy of the Hymenophyllaceae, Schizaeaceae, and Gleicheniaceae. II. Schizaeaceae. Annals of Botany, xv.

(2) Id. III. Gleicheniaceae. Annals of Botany, xv.

(3) Id. IV. Further observations on Schizaea. Annals of Botany, xvii.

Brebner. On the anatomy of Danaea and other Marattiaceae. Annals of Botany, xvi.

Chandler. On the arrangement of the vascular strands in the 'seedlings' of certain Leptosporangiate Ferns. Preliminary note. New Phytologist, May, 1904.

DE BARY. Comparative anatomy of the Phanerogams and Ferns. I884.

Farmer and Hill. On the arrangement of the vascular strands in Angiopteris evecta, and some other Marattiaceae. Annals of Botany, xvi.

FAull. The anatomy of the Osmundaceae. Botanical Gazette, xxxii.

FORD. The anatomy of Ceratopteris thalictroides, L. Annals of Botany, xvi.

Gerard. Recherches sur le passage de la racine à la tige. Ann. Sc. Nat., $6^{\theta}$ sér., t. xi.

Gwynne-Vaughan. (I) Polystely in the genus Primula. Annals of Botany, xi.

(2) Observations on the anatomy of Solenostelic Ferns. Annals of Botany, xi.

Botany, xvii.

(3) Observations on the anatomy of Solenostelic Ferns. II. Annals of

Holle. Ueber Bau und Entwicklung der Vegetationsorgane der Ophioglosseen. Bot. Zeitung, 1875 .

JefFrey. (I) Transactions of the British Association. Toronto, I 897.

(2) Morphology of the central cylinder of Angiosperms. Transactions of the Canadian Institute, 1900.

(3) Structure and development of the stem in the Pteridophyta and Gymnosperms.

Phil, Trans., ser. B, vol, cxcv (1902). 
Lachmann. Contributions, \&c. Thésis présentée à la Faculté des Sciences de Paris. Sér. A, No. I 6 .

Leclerc du Sablon. Recherches sur la formation de la tige dans les Fougères. Ann. Sc. Nat., $\tau^{\mathrm{e}}$ sér., t. xi.

Schoute. Die Stelär-Theorie. Groningen, I902.

SEWARD And Ford. The anatomy of Todea. Trans. Linn. Soc., and ser., vol. vi.

TANSLey. The Stelar Theory. Science Progress, 1896.

Tansley and Lulham. (I) On a new type of Fernstele. Annals of Botany, xvi.

(2) The vascular system of the rhizome and leaf-trace of Pteris aquilina, L., and Pteris incisa, Thunb., var. integrifolia, Beddome. New Phytologist, iii, I904.

Tansley ANd CHICK. On the anatomy of Schizaea malaccana. Annals of Botany, xvii.

Trécul. Remarques sur la position des trachées dans les Fougères. Ann. Sc. Nat., $5^{e}$ sér., t. xii. Van Tieghem. Sur la polystélie. Ann. Sc. Nat., $7^{e}$ sér., t. iii.

Zenettr. Das Leitungssystem im Stamm von Osmunda regalis. Bot. Zeit., 1895.

\title{
EXPLANATION OF FIGURES IN PLATES XVIII, XIX, AND XX.
}

\author{
Illustrating Dr. Chandler's paper on the Vascular Strands in Ferns.
}

In the diagrammatic figures the following scheme has been adopted :-Endodermis: Represented by a broken line. Phloem : Shaded. Xylem: Unshaded.

Figs. I-1 2. Doodia aspera, R. Br.

Figs. I3-35. Lomaria gibba, Labill. $r$. root.

Figs. 36-50. Nephrodium hirtipes, Hk. r. root, lt. leaf-trace.

Figs. 51-76. Lomaria Spicant, Desv. $r$. root, lt. leaf-trace.

Figs. 77-90. Asplenium nidus, L. St. Sieve-tube, $r$. root, lt. leaf-trace, i.e. internal endodermis.

Figs. 9I-I 28. Polypodium aureum, L. Lt. leaf-trace, $d$. lt. double leaf-trace, $r$. root, $p$. $s$. petiolar strand.

Figs. I29-132. Aspidium falcatum, Sw. It. leaf-trace.

Figs. I33-I 5 I. Nephrolepis cordifolia, Hk. c. s. cauline strand, stl. stolon, px. protoxylem, $r$. root, $l t$. leaf-trace.

Figs. 152-164. Asplenium bulbiferum, Forst. $E$. Endodermal cells, $l t$. leaf-trace, $r$. root.

Figs. 165-171. Aspidium Tsus-Simense, Hk. lt. leaf-trace.

Figs. $172-19^{6}$. Nothochlaena sinuata, Kaulf. $L t$. leaf-trace, $r$. root, scl. sclerenchyma

Fig. 197. Doodia aspera, R. Br. Protostele.

Fig. I98. Doodia aspera, K. Br. Differentiation of parenchyma at the centre of the solid xylem rod; $p$. parenchyma cells.

Fig. 199. Doodia aspera, R. Br. Differentiation of internal phloem; ph. phloem.

Fig. 200. Loodia aspera, R. Br. Transverse section of cauline vascular system after the exit of the first leaf-trace.

Fig. 20I. Doodia aspera, R. Br. Transverse section of cauline system after the repair of the first leaf-gap ; st. sieve-tubes.

Fig. 202. Nephrodium setigerum, Baker. Transverse section of the vascular system before the differentiation of the first leaf-trace. Isolated tracheides are shown in the central phloem.

Fig. 203. Nephrodium setigerum, Baker. Transverse section through vascular system at the region of a ground-tissue pocket ; i.e. inner endodermis, o. e. outer endodermis, $l t$. leaf-trace.

Figs. 204-207. Polypodium aureum, L. Transverse sections of petiole at successively higher levels, showing the gradual fusion of the two petiolar strands.

Fig. 208. Polypodium aureum, L. Transverse section of rhizome showing wound-periderm. 
(3)

3
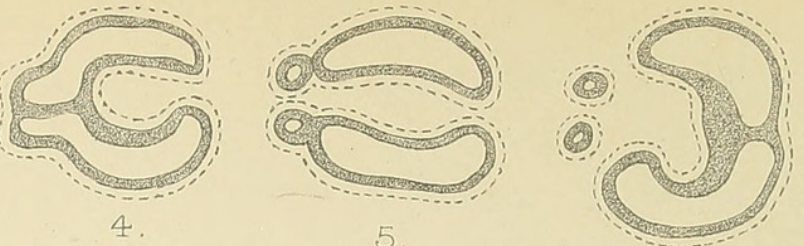

(8)
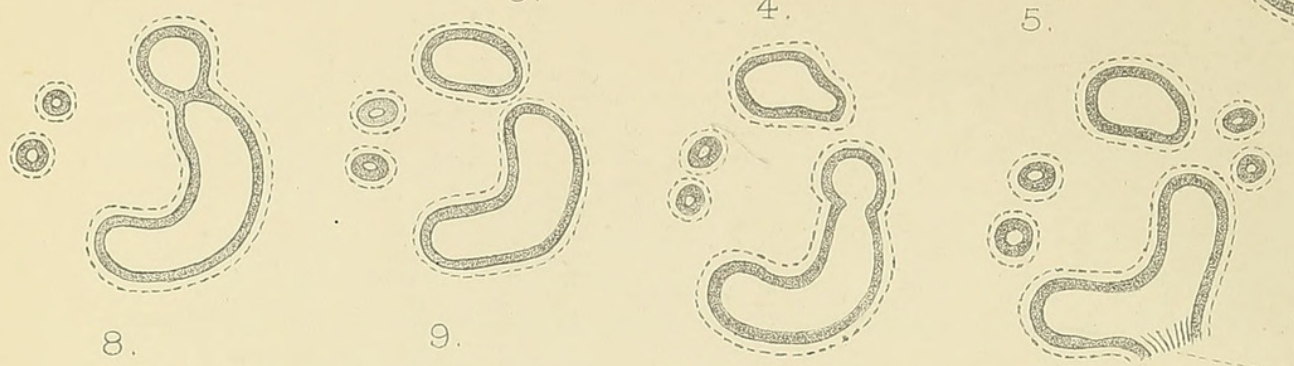

6.
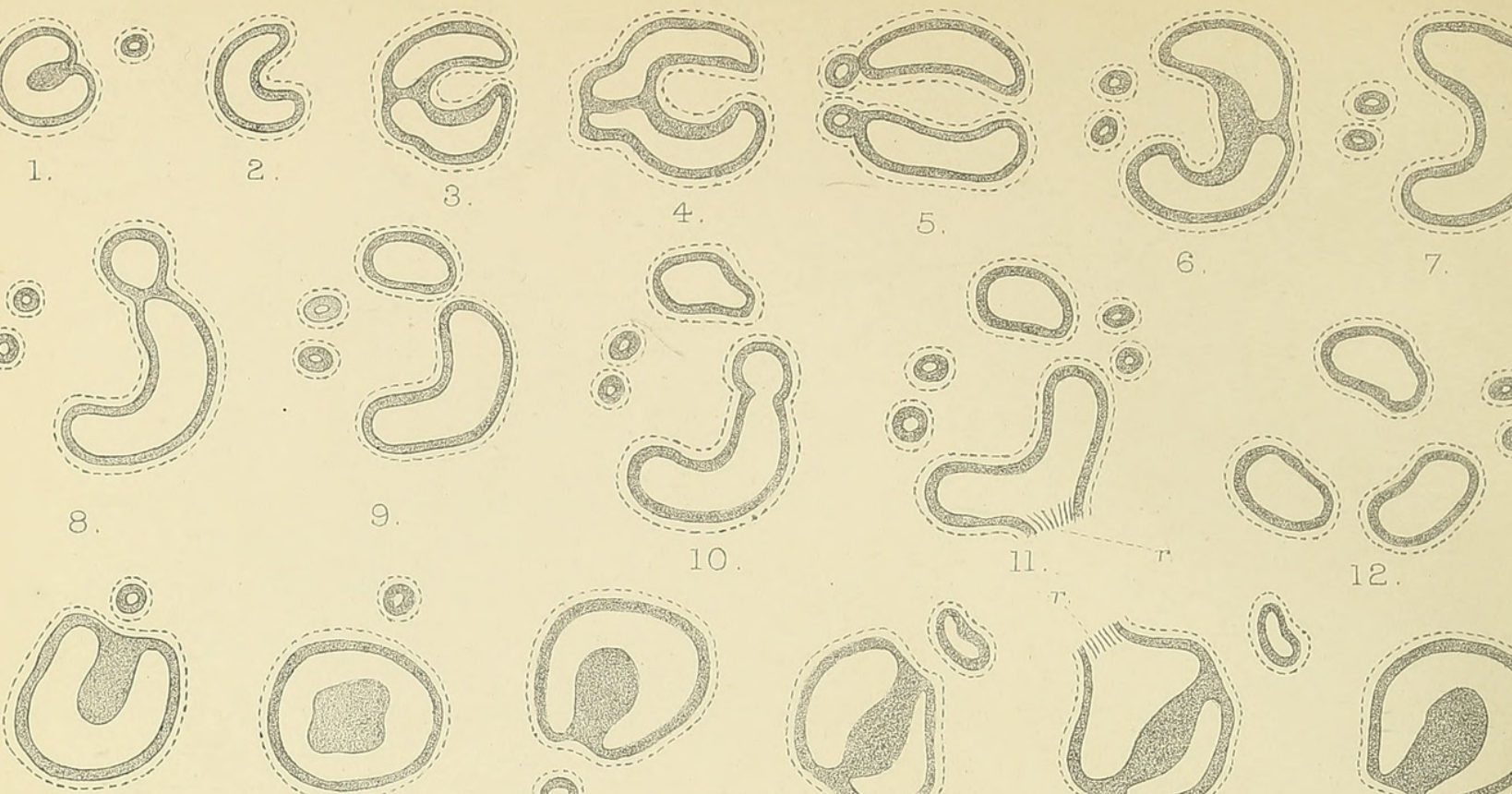

不
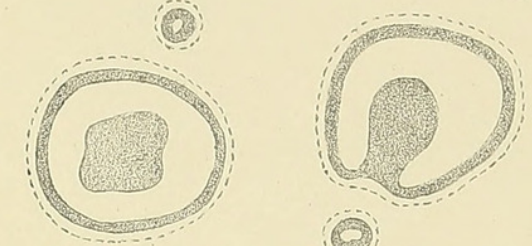

(3)

O.

11

(1)

(1)

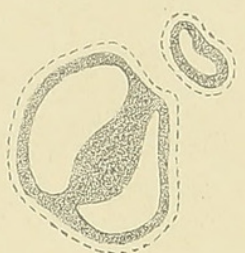

16.
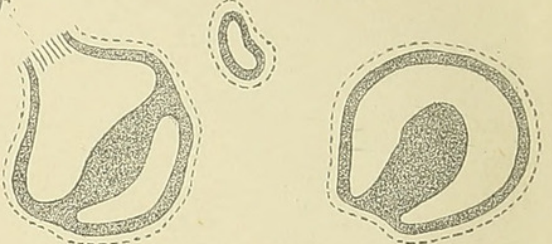

18
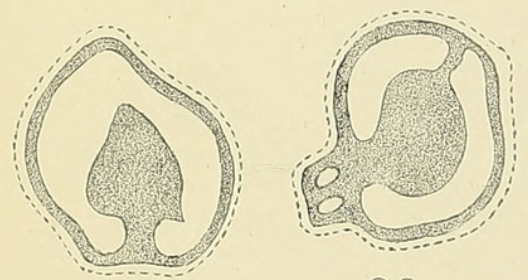

20.

21
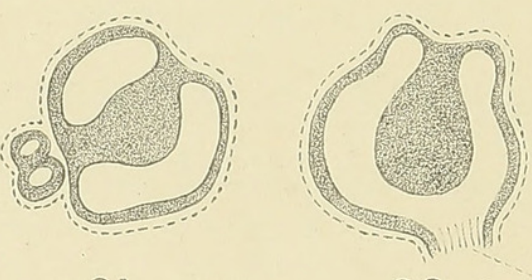

22 .

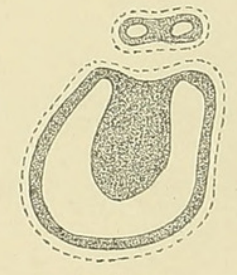

23.

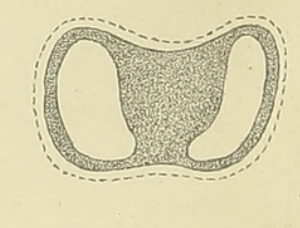

(n)<smiles>O=S1(=O)c2ccccc2-c2ccccc21</smiles>

$(0)$

(

(6)

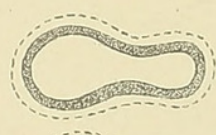

Sil

(1)

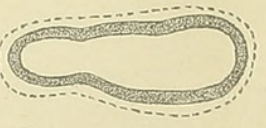

(0)<smiles>c1ccc2ccccc2c1</smiles>

31.
용<smiles>O=S1(=O)C=CC=CC=CC=CC=CC=C1</smiles>

32

28.

29

(

(1)

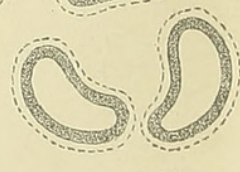

34

36.

$$
39
$$

$y 93^{\circ} 30^{\circ} 0^{\circ} 00^{\circ}$ 43. $T .44$ 


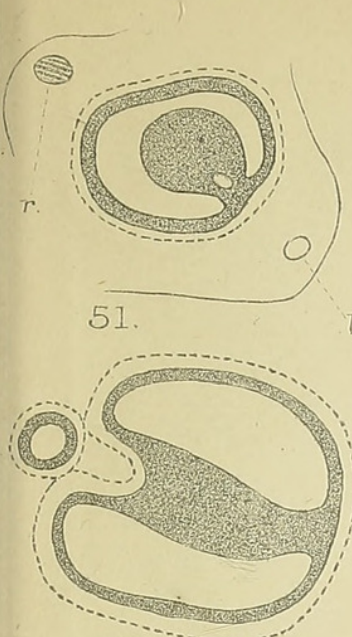

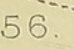

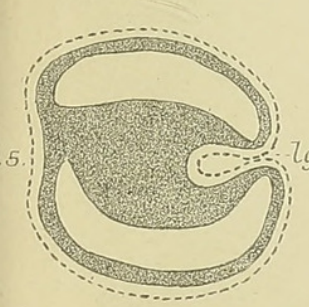

61.

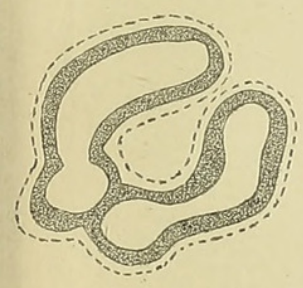

66.
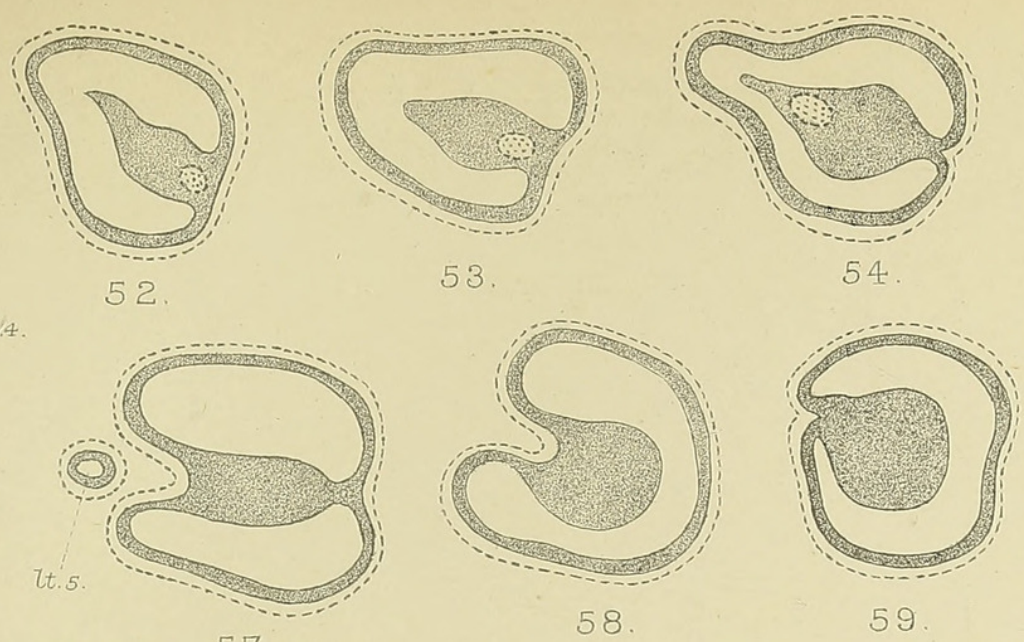

57

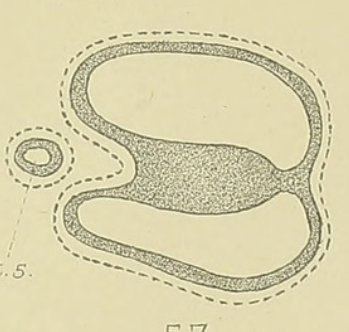

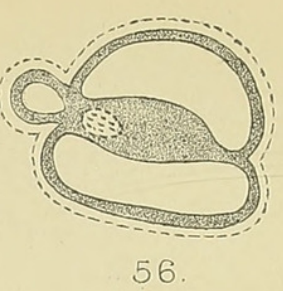
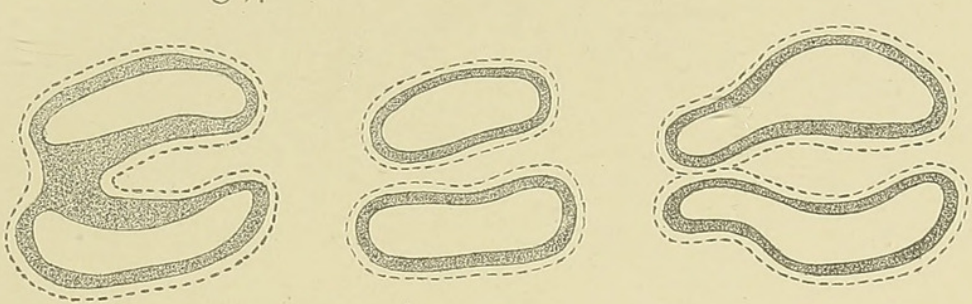

63.

64

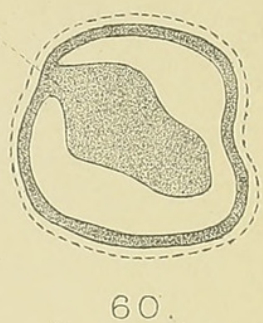

62.
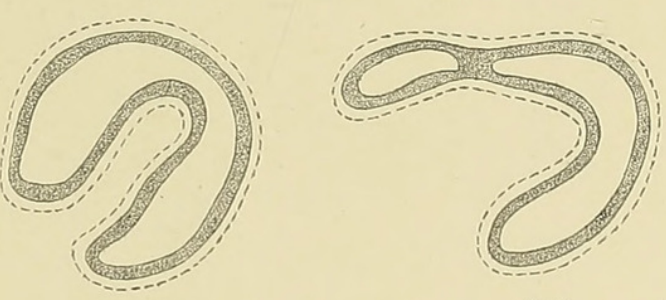

68
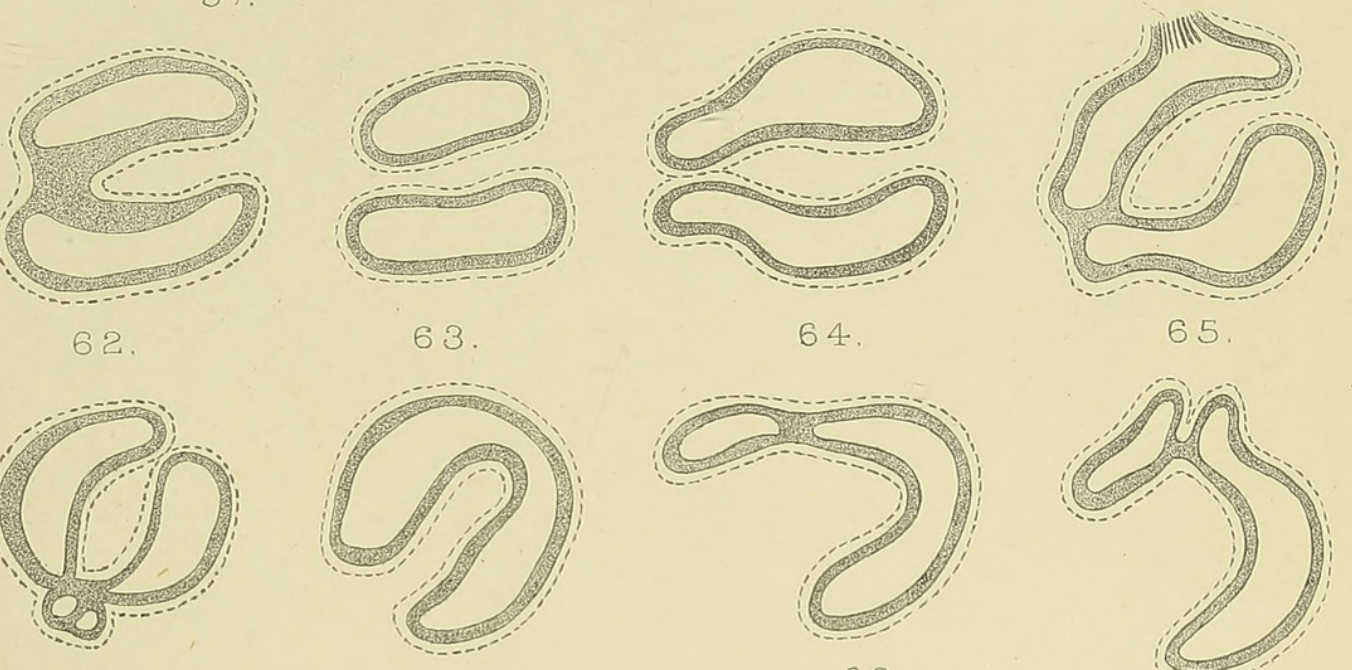

6.7.
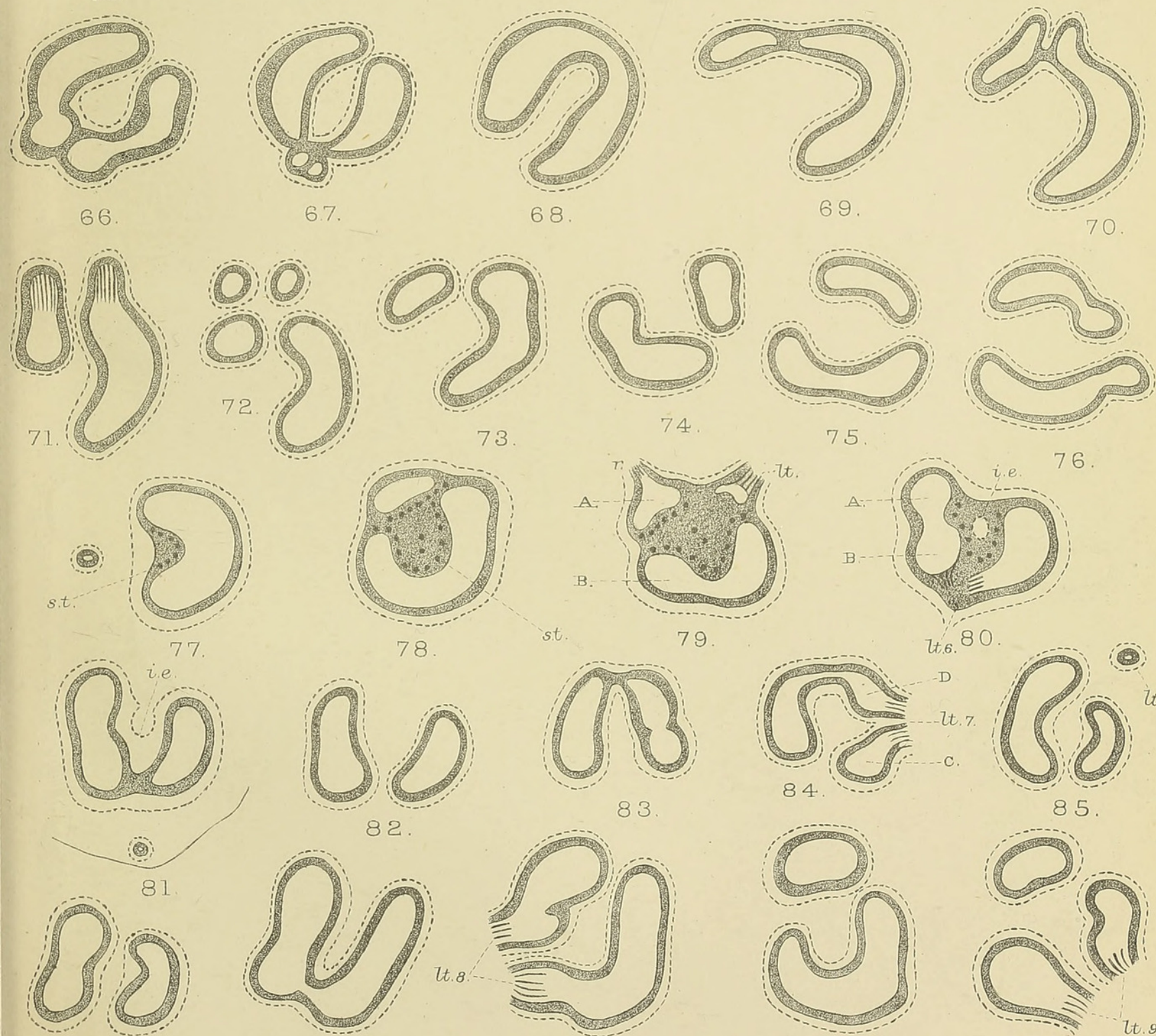

86

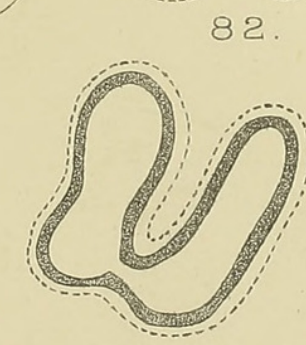

87

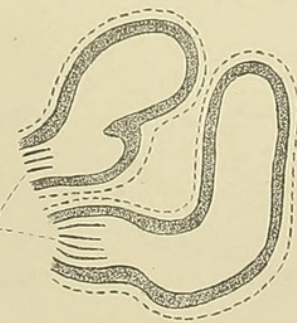

88.

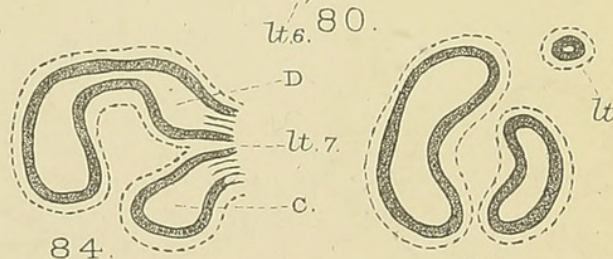

84.

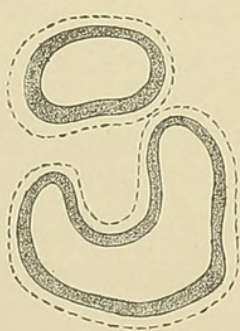

89

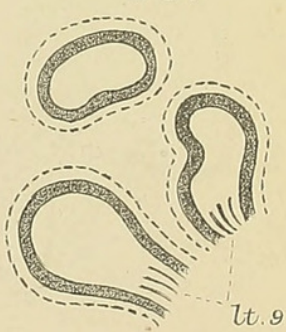

90. 


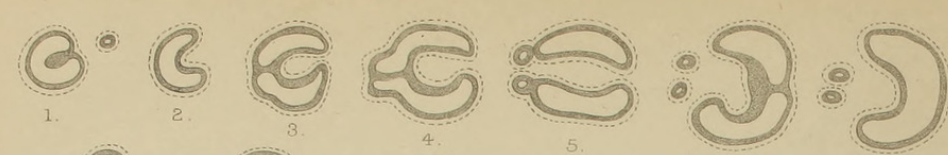
Q 000

$: \beta: 3: 3: 0: 0$

(1) (2) $0^{\circ}$

(2) 58

(1).8@000

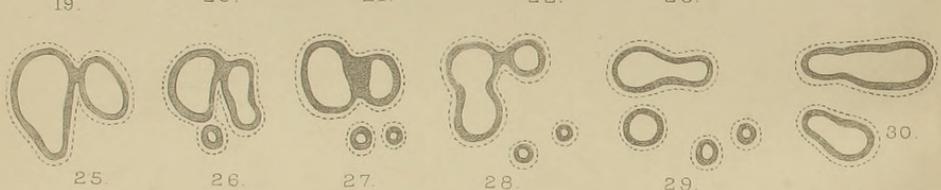

$: 0: \delta: \infty: 0: 0$

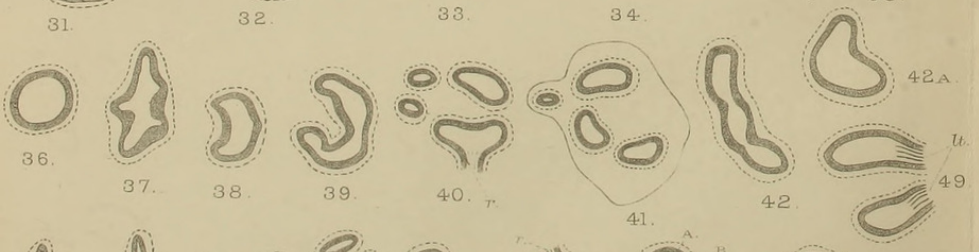

INC $C^{\circ} 80: 500$
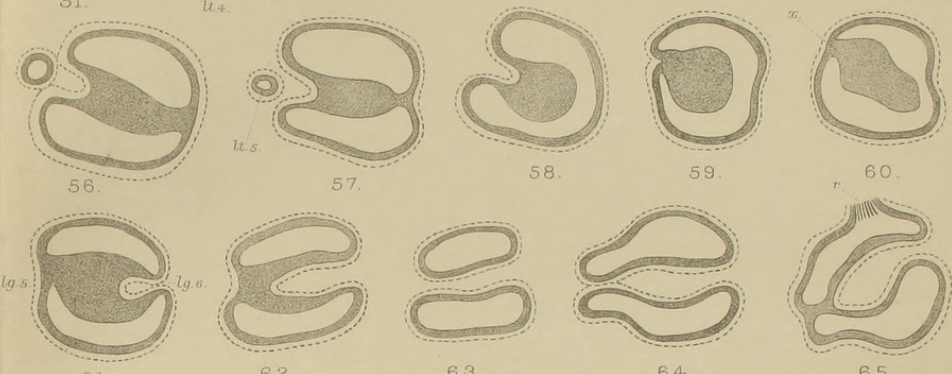

(c)

बृ

Q

(2)

64

Of:0 $00 \mathrm{~B} \approx 3$ - 0

(7) 8

(2)

BO BO OB है $80^{\circ}$

80

86
2) 3

87
¿े

89

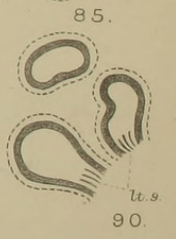


- Annals of Botany.

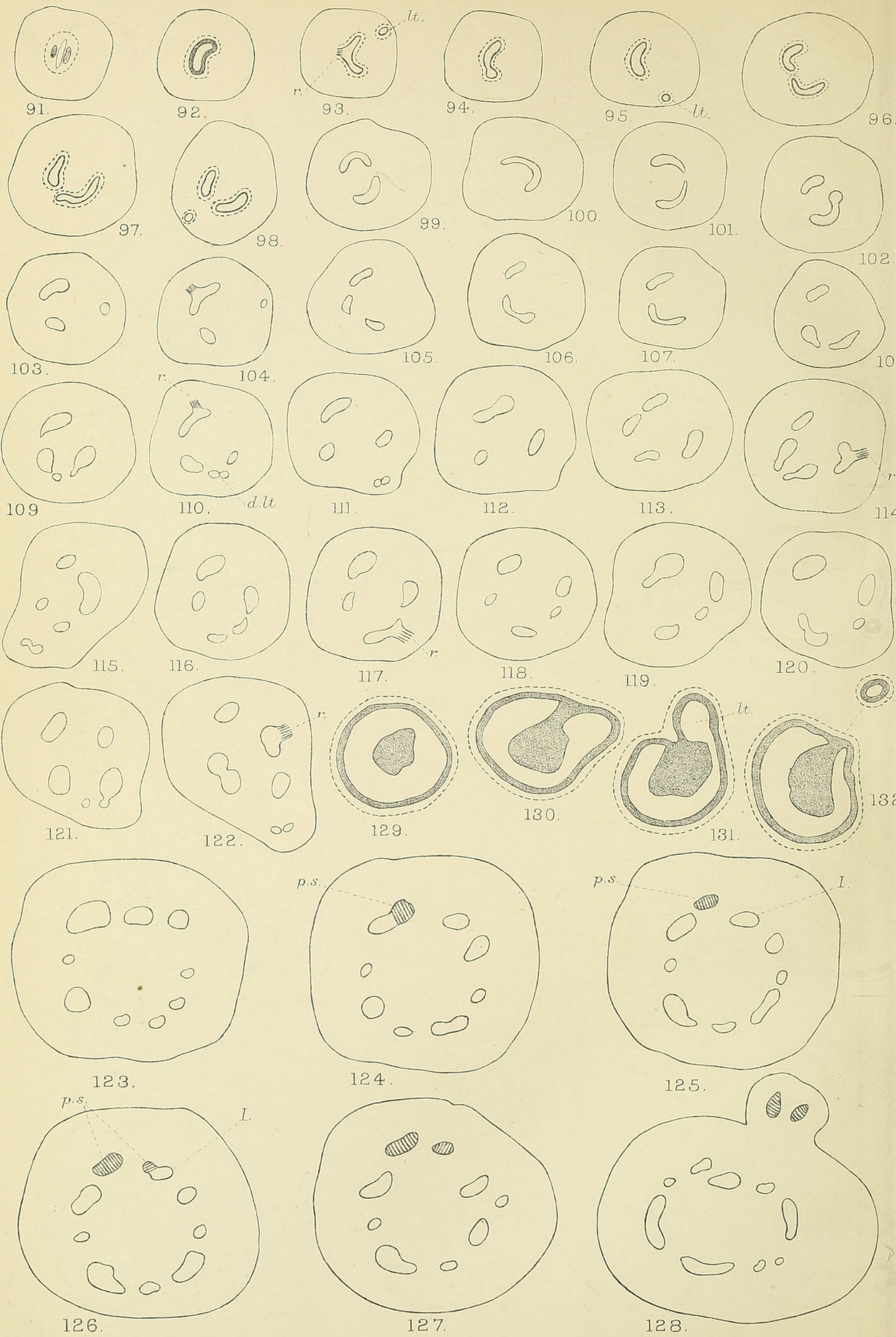




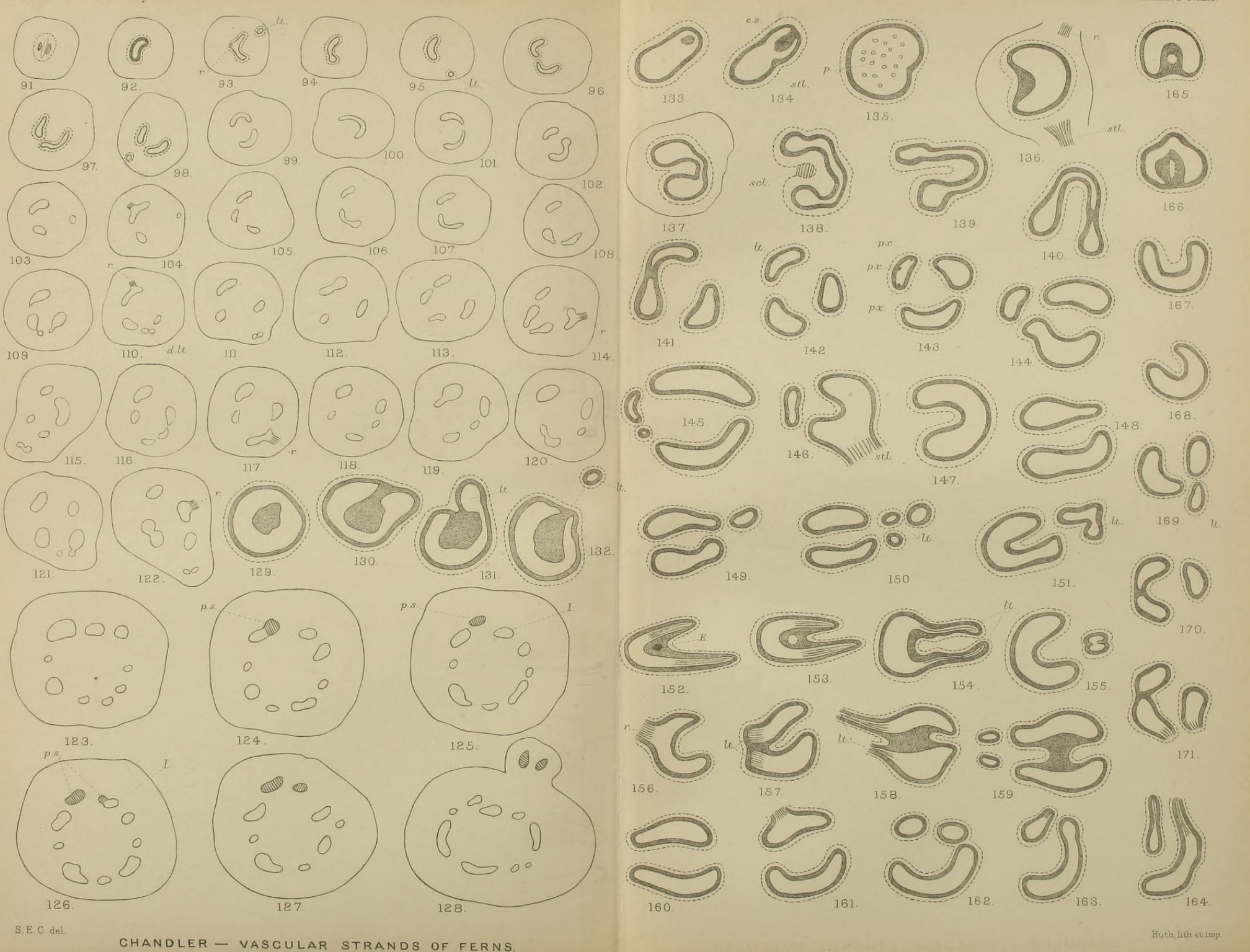


Annals of Botany.
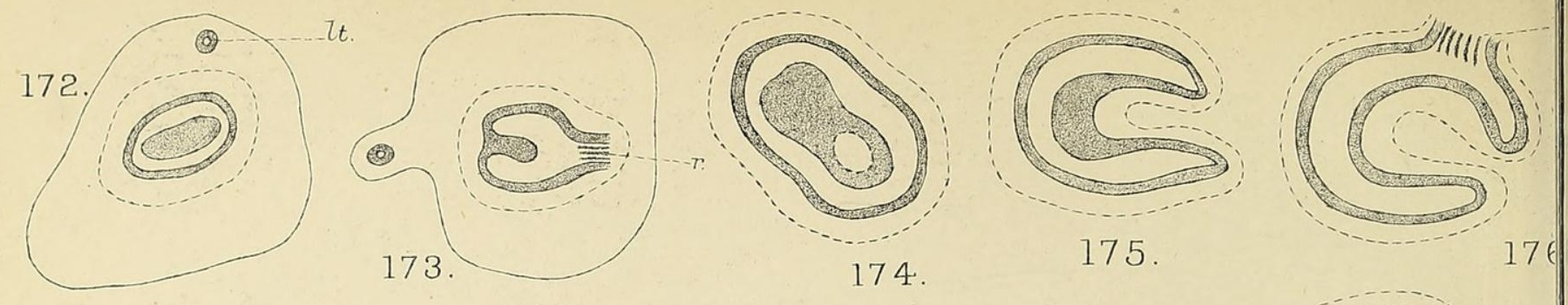

173.

174.

175.

$17 t$

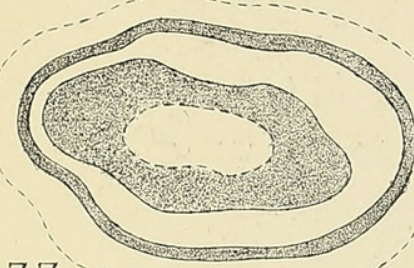

${ }_{177 .}$
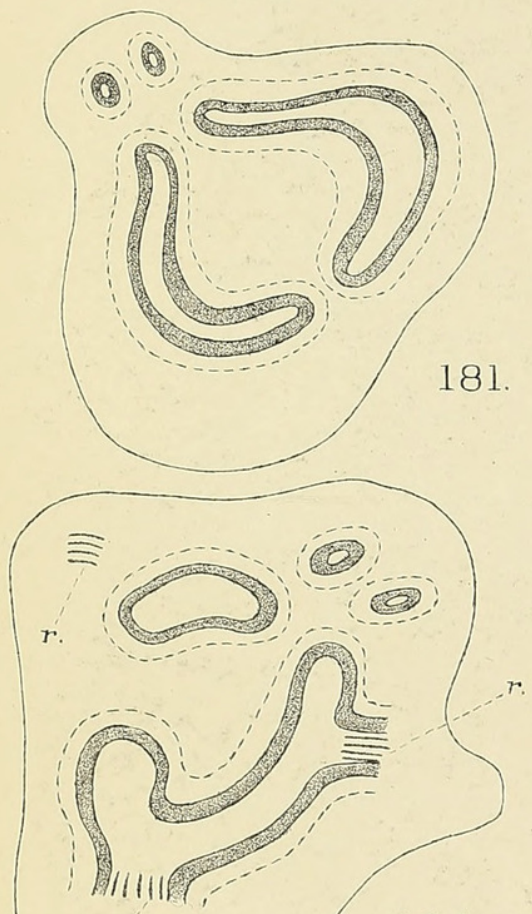

184
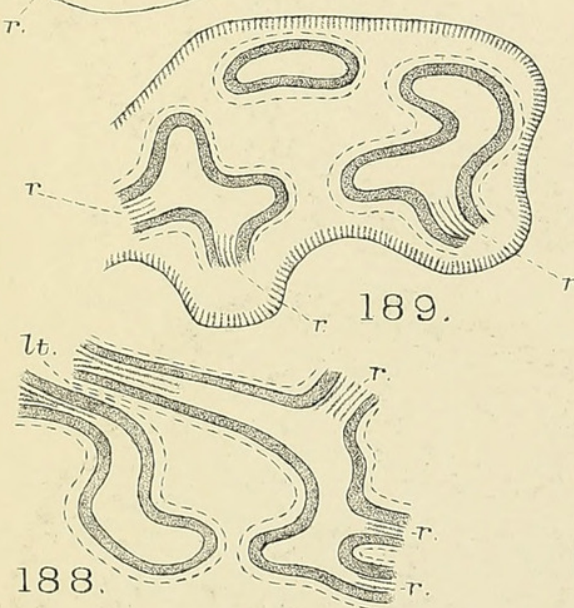

It.

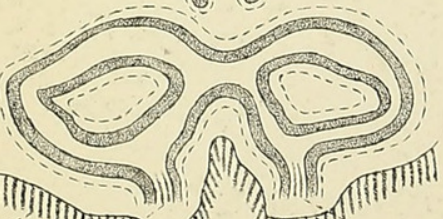

IIn⿴囗十

194.

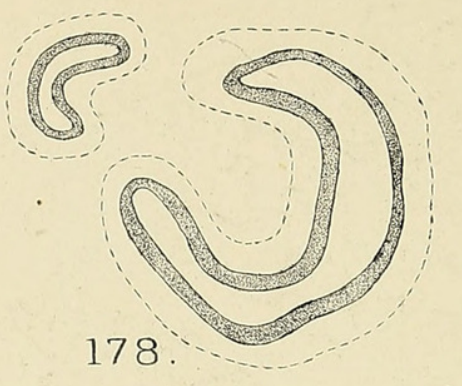

178
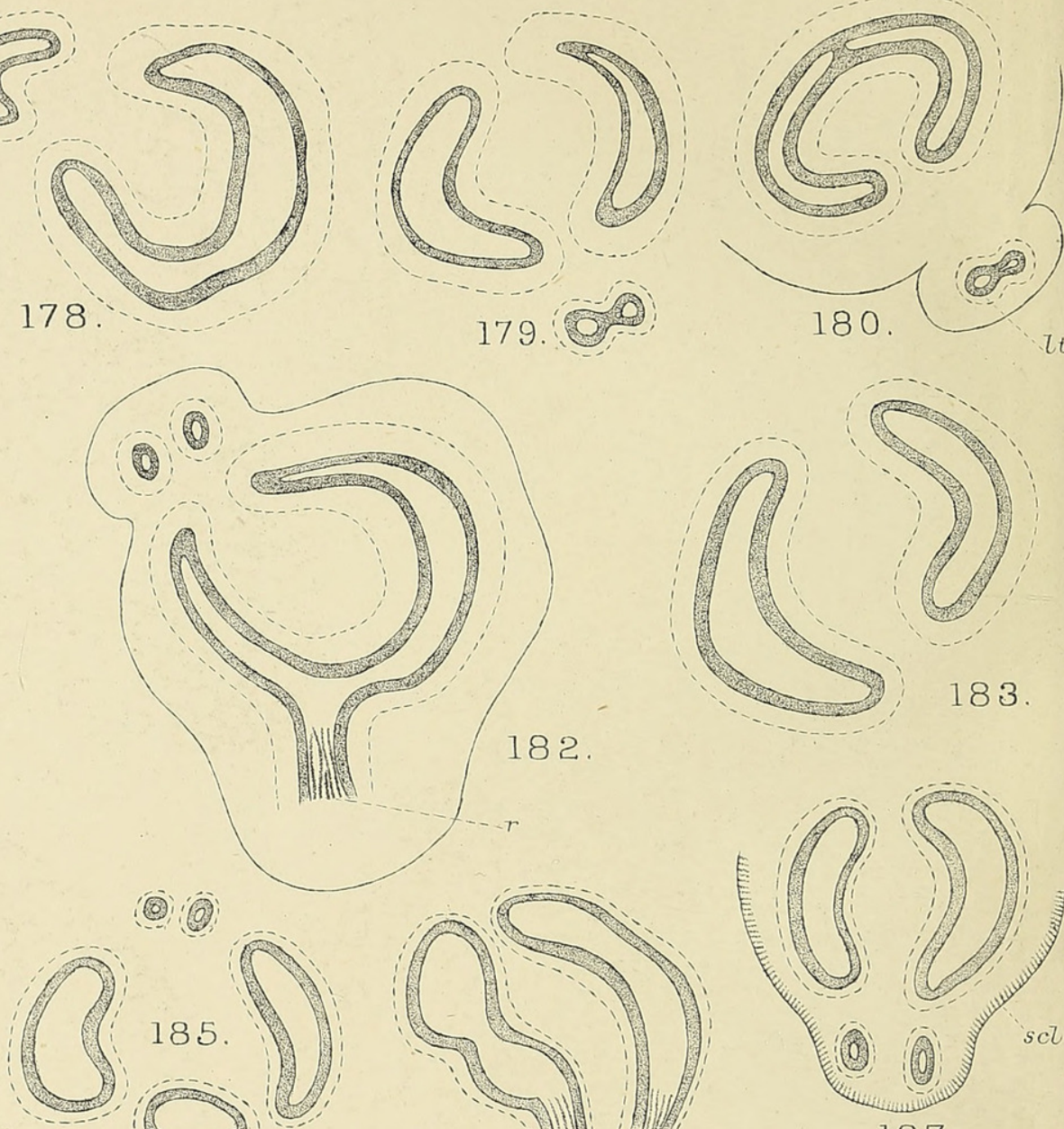

(0)
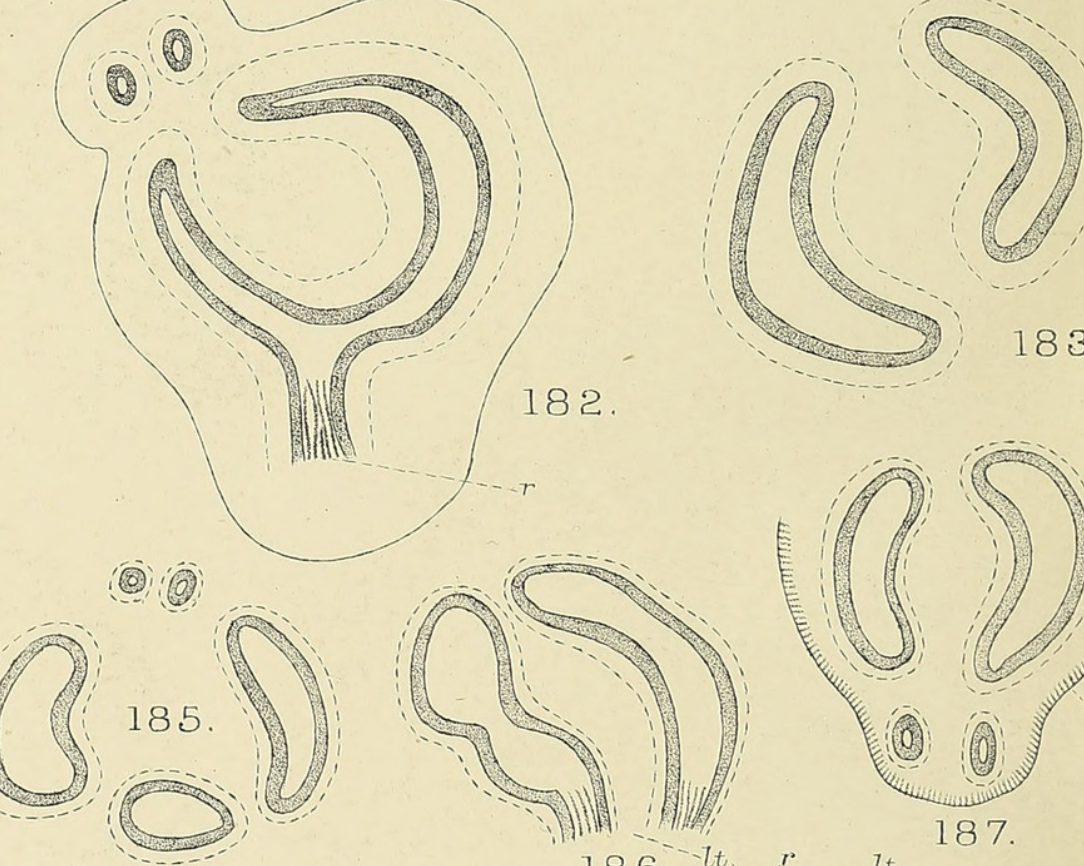

183.

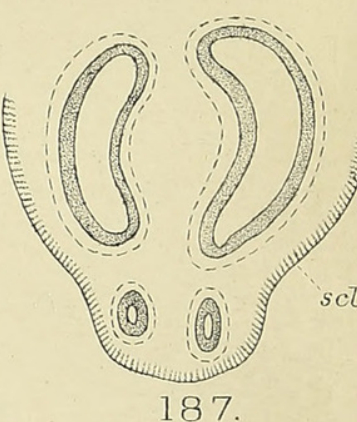

$186-t t r$
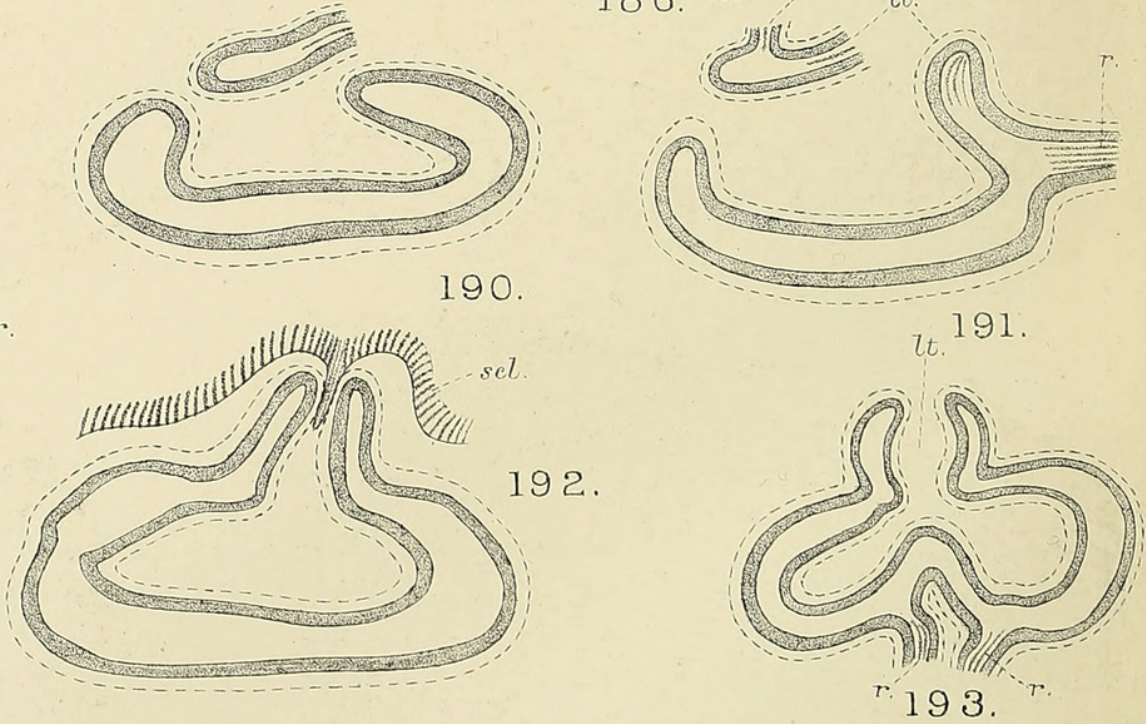

r. 193.
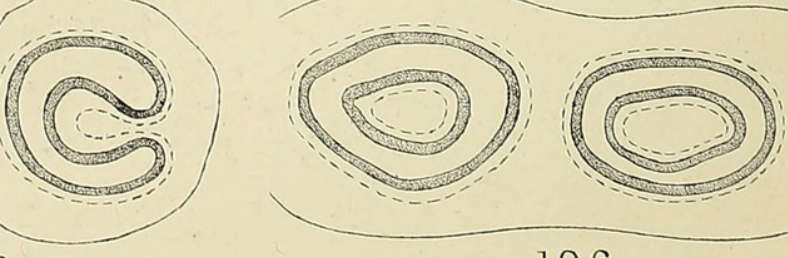

$$
\text { , }
$$

$$
\text { CHANDLER - VASCU }
$$



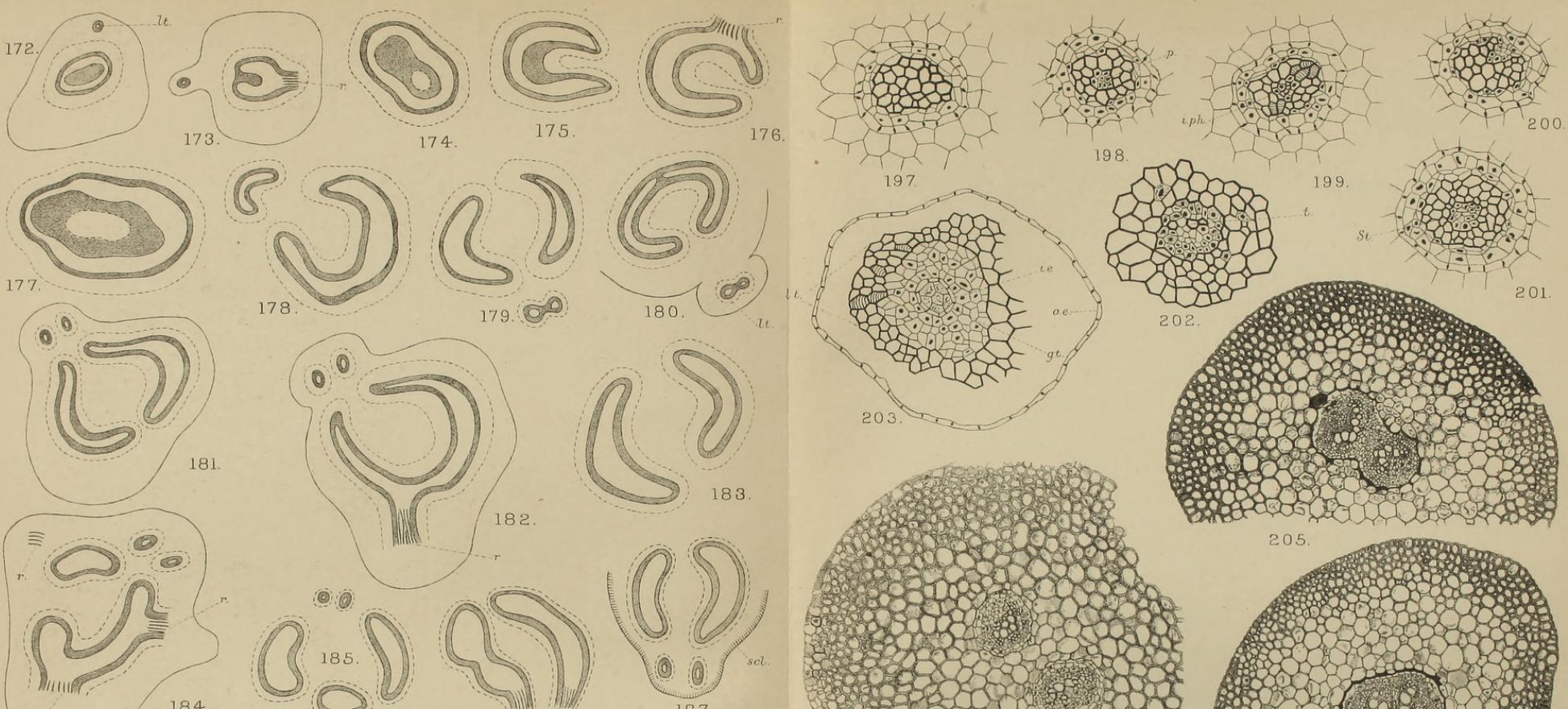

$$
\text { तु? }
$$
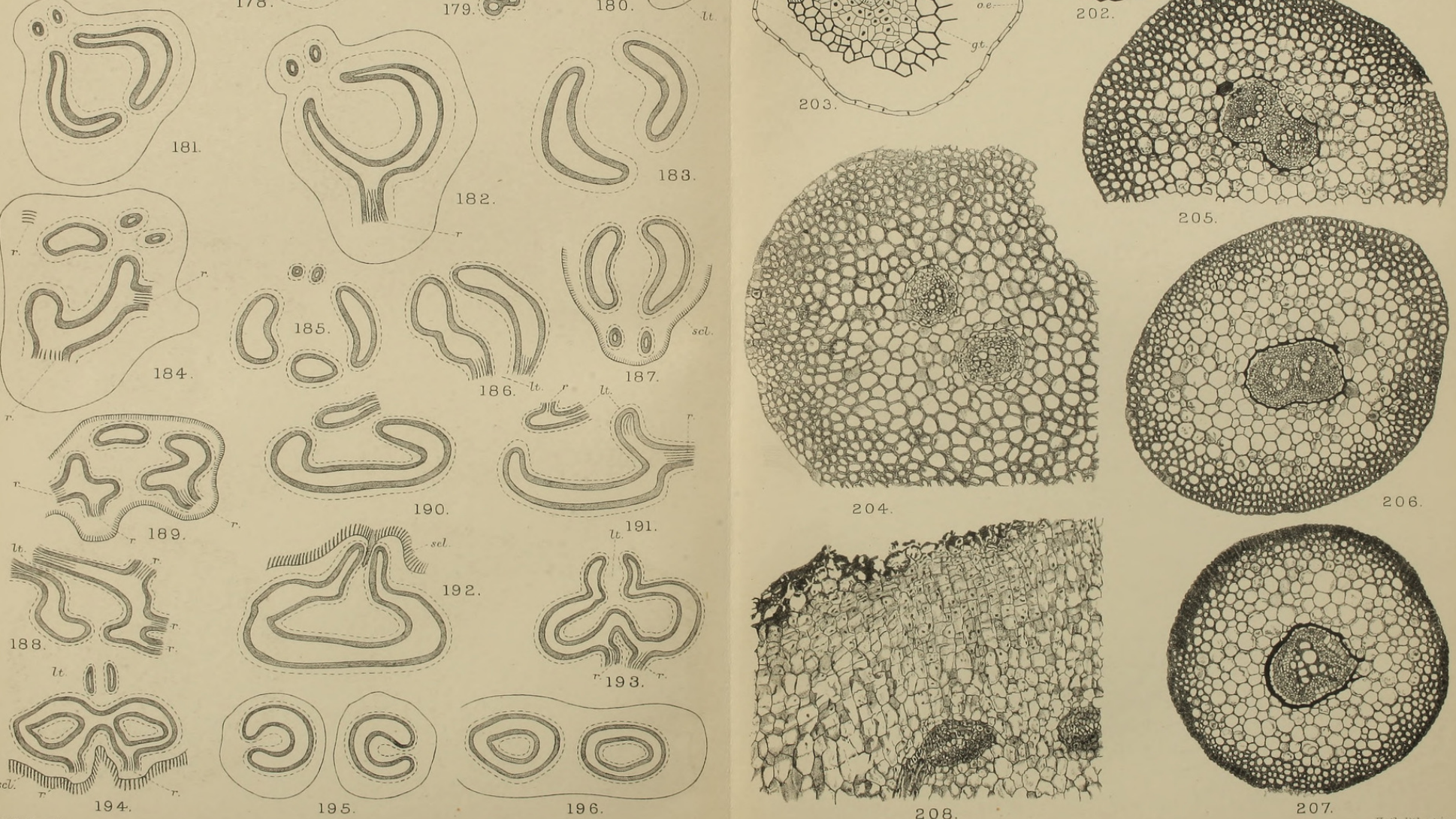

CHANDLER - VASCULAR STRANDS OF FERNS. 


\section{$2 \mathrm{BHL}$ Biodiversity Heritage Library}

Chandler, S. E. 1905. "On the arrangement of the vascular strands in the 'seedlings' of certain leptosporangiate ferns." Annals of botany 19, 365-410. https://doi.org/10.1093/oxfordjournals.aob.a089007.

View This Item Online: https://www.biodiversitylibrary.org/item/233541

DOI: https://doi.org/10.1093/oxfordjournals.aob.a089007

Permalink: https://www.biodiversitylibrary.org/partpdf/318805

\section{Holding Institution}

Smithsonian Libraries

\section{Sponsored by}

Biodiversity Heritage Library

\section{Copyright \& Reuse}

Copyright Status: Not in copyright. The BHL knows of no copyright restrictions on this item.

This document was created from content at the Biodiversity Heritage Library, the world's largest open access digital library for biodiversity literature and archives. Visit BHL at https://www.biodiversitylibrary.org. 